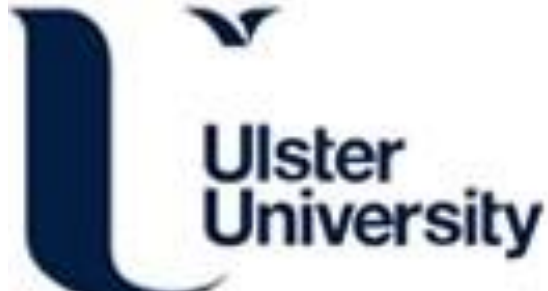

\section{Modification of 1D TiO2 nanowires with GaOxNy by atomic layer deposition for TiO2@GaOxNy core-shell nanowires with enhanced photoelectrochemical performance}

Tao, J-J., Ma, H-P., Yuan, K-P., Gu, Y., Lian, J-W., Li, X-X., Huang, W., Nolan, M., Lu, H-L., \& Zhang, D-W. (2020). Modification of 1D TiO2 nanowires with GaOxNy by atomic layer deposition for TiO2@GaOxNy coreshell nanowires with enhanced photoelectrochemical performance. Nanoscale, 12(13), 7159-7173. https://doi.org/10.1039/c9nr10908k

Link to publication record in Ulster University Research Portal

Published in:

Nanoscale

Publication Status:

Published (in print/issue): 24/02/2020

DOI:

10.1039/c9nr10908k

Document Version

Author Accepted version

\section{General rights}

Copyright for the publications made accessible via Ulster University's Research Portal is retained by the author(s) and / or other copyright owners and it is a condition of accessing these publications that users recognise and abide by the legal requirements associated with these rights.

\section{Take down policy}

The Research Portal is Ulster University's institutional repository that provides access to Ulster's research outputs. Every effort has been made to ensure that content in the Research Portal does not infringe any person's rights, or applicable UK laws. If you discover content in the Research Portal that you believe breaches copyright or violates any law, please contact pure-support@ulster.ac.uk. 


\section{Modification of $1 \mathrm{D} \mathrm{TiO}_{2}$ nanowires with $\mathrm{GaO}_{\mathrm{x}} \mathrm{N}_{\mathrm{y}}$ by atomic layer deposition for $\mathrm{TiO}_{2} @ \mathrm{GaO}_{\mathrm{x}} \mathrm{N}_{\mathrm{y}}$ core-shell nanowires with enhanced photoelectrochemical performance}

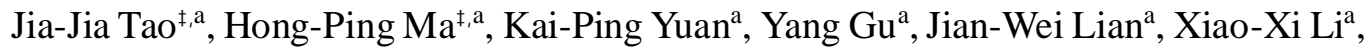
Wei Huanga , Michael Nolan ${ }^{\text {b,* }}$, Hong-Liang Lu ${ }^{\mathrm{a},{ }^{*}}$ and David-Wei Zhang ${ }^{\mathrm{a}}$

a State Key Laboratory of ASIC and System, Shanghai Institute of Intelligent Electronics \& Systems, School of Microelectronics, Fudan University, Shanghai 200433, China

${ }^{\mathrm{b}}$ Tyndall National Institute, University College Cork, Lee Maltings, Dyke Parade, Cork T12 R5CP, Cork, Ireland

E-mail: Michael.nolan@tyndall.ie (M. Nolan), honglianglu@ fudan.edu.cn (H-L Lu);

‡, These authors contributed equally 


\section{Abstract}

As a well known semiconductor that can catalyse the oxygen evolution reaction, $\mathrm{TiO}_{2}$ has been extensively investigated for its solar photoelectrochemical water properties. Unmodified $\mathrm{TiO}_{2}$ shows some issues, particularly with respect to its photoelectrochemical performance. In this paper, we present a strategy for the controlled deposition of controlled amounts of $\mathrm{GaO}_{\mathrm{x}} \mathrm{N}_{\mathrm{y}}$ cocatalysts on $\mathrm{TiO}_{2}$ 1D nanowires $\left(\mathrm{TiO}_{2} @ \mathrm{GaO}_{\mathrm{x}} \mathrm{N}_{\mathrm{y}}\right.$ core-shell) using atomic layer deposition. We show that this modification significantly enhances the photoelectrochemical performance compared to pure $\mathrm{TiO}_{2} \mathrm{NW}$ photoanodes. For our most active $\mathrm{TiO}_{2} @ \mathrm{GaO}_{\mathrm{x}} \mathrm{N}_{\mathrm{y}}$ core-shell nanowires with a $\mathrm{GaO}_{\mathrm{x}} \mathrm{N}_{\mathrm{y}}$ thickness of $20 \mathrm{~nm}$, a photocurrent density up to $1.10 \mathrm{~mA}$ $\mathrm{cm}^{-2}$ (at $1.23 \mathrm{~V} v s$ RHE) under AM $1.5 \mathrm{G}$ irradiation $\left(100 \mathrm{~mW} \mathrm{~cm}^{-2}\right)$ has been achieved, which is 14 times higher than that of unmodified $\mathrm{TiO}_{2} \mathrm{NWs}$. Furthermore, the band gap matching with $\mathrm{TiO}_{2}$ enhances absorption of visible light over unmodified $\mathrm{TiO}_{2}$ and the facile oxygen vacancy formation after deposition of $\mathrm{GaO}_{x} \mathrm{~N}_{y}$ also provides active sites for water activation. Density functional theory studies of model systems of $\mathrm{GaO}_{\mathrm{x}} \mathrm{N}_{\mathrm{y}^{-}}$ modified $\mathrm{TiO}_{2}$ confirm the band gap reduction, high reducibility and ability to activate 
water. The highly efficient and stable systems of $\mathrm{TiO}_{2} @ \mathrm{GaO}_{\mathrm{x}} \mathrm{N}_{\mathrm{y}}$ core-shell nanowires with ALD deposited $\mathrm{GaO}_{\mathrm{x}} \mathrm{N}_{\mathrm{y}}$ demonstrates a good strategy for fabrication of core-shell structures that enhances the photoelectrochemical performance of readily available photoanodes.

Keywords: $\quad \mathrm{TiO}_{2} @ \mathrm{GaO}_{\mathrm{x}} \mathrm{N}_{\mathrm{y}} \quad$ nanowires; $\quad$ Core-shell nanoarchitecture; Photoelectrochemical performance; Atomic layer deposition. 


\section{Introduction}

As a potentially efficient and sustainable strategy for addressing the global energy problem, particularly for the production of hydrogen, the photocatalytically driven splitting of water using semiconductor catalysts has been widely studied and applied in modern society. ${ }^{1,2}$ During recent decades, photocatalytic systems based on two or more semiconductors have been constructed to meet the requirements for a high photoelectrochemical (PEC) activity for water splitting. ${ }^{3,4}$ In general, in these systems, one semiconductor material can enhance light absorption while the second semiconductor material can provide more reaction sites and catalytic activity. Additionally, the energy level matching between the two semiconductors can drive effective charge separation and transfer of electrons $\left(\mathrm{e}^{-}\right)$and holes $\left(\mathrm{h}^{+}\right)$at the interfaces or junctions. ${ }^{5}$ Since Fujishima et al. $^{6}$ first studied the PEC performance for electrochemical photocatalysis of water over $\mathrm{TiO}_{2}, \mathrm{TiO}_{2}$ based materials with different size, structure, morphology, or crystal phase have been widely studied and reported for their environmentally benign nature, stability, and cost-efficiency. ${ }^{7}$ In terms of nanostructures, one-dimensional $\mathrm{TiO}_{2}$ nanoarrays, including nanowires (NWs), nanotubes (NTs) and nanorods (NRs), have proven to be promising photoanode materials due to unique geometric advantages offered by these structures. These nanoarray-based semiconductor materials show large specific surface area and enhanced activity, as well as a direct transport path for charge carriers. ${ }^{8-10}$

Despite their advantages, the practical application of $\mathrm{TiO}_{2}$ nanoarrays still faces 
two primary problems. One is the large band gap which means that $\mathrm{TiO}_{2}$ can only absorb ultraviolet light, which results in a low utilization rate of sunlight, and low energy conversion. The second problem is that the photogenerated excitons (i.e. $\mathrm{e}^{-}$and $\mathrm{h}^{+}$) in the conduction (CB) and valence bands (VB) show high recombination rates for both radiative and non-radiative processes, which greatly reduces the efficiency of PEC water splitting. ${ }^{11}$ Heterojunctions or interfacial structures using narrow bandgap semiconductors together with $\mathrm{TiO}_{2}$ is a well-studied strategy to address these problems.

In recent work, it has been discussed that photocatalysts using cations with $d^{10}$ electronic configurations such as $\mathrm{Se}^{4+}, \mathrm{Ge}^{4+}, \mathrm{In}^{3+}, \mathrm{Sb}^{5+}$, and $\mathrm{Ga}^{3+}$ ions ${ }^{12-14}$ can realize visible light catalytic reaction. The enhanced performance is suggested to come from high band dispersion of hybridized $s p$ orbitals in semiconductors with $d^{10}$ conduction bands, which promotes high electron mobility to enhance the photocatalytic performance. ${ }^{15}$ In addition, many researchers focus on the group III nitrides for their excellent optical and unique semiconductor properties. Previously, Bae et al. ${ }^{16}$ reported bulk GaN for sustained water splitting due to its chemical stability and suitable CB and VB levels. However, the large band gap of $3.4 \mathrm{eV}$ of phase-pure GaN limits absorption of visible light, and the recombination of photogenerated $\mathrm{e}^{-}$and $\mathrm{h}^{+}$also hinders water oxidation. Alternatively, Hassan et al. ${ }^{17}$ fabricated $\mathrm{ZnS} / \mathrm{GaN}$ photoanodes for enhancing PEC performance, which was ascribed to the type-II band alignment of the heterojunction. Additionally, Ma et al. ${ }^{18}$ designed $\mathrm{ZnO}-\mathrm{GaON}$ core-shell nanowires resulting in high PEC performance which can be tuned by the thickness of the $\mathrm{GaON}$ 
layer. Interestingly, Patil et al. ${ }^{19}$ developed the GaN/ZnO/MWCNTs photoanode, which showed high the PEC performance under visible light irradiation. This improved performance is attributed to the presence of $\mathrm{Zn} 3 d$ and $\mathrm{N} 2 p$ orbitals in the upper VB, which provides the $p-d$ repulsion to shift the VB maximum upwards and reduce the band gap. ${ }^{20}$ Similarly, Khan et al. ${ }^{21}$ prepared a $\mathrm{GaON} / \mathrm{ZnO}$ nanoarchitecture with increased hole mobility for PEC performance, which arises from the large dispersion of hybridized O 2p, Zn 3d, and N 2p orbitals.

Hence, taking advantage of the band dispersion in $\mathrm{GaO}_{\mathrm{x}} \mathrm{N}_{\mathrm{y}}$, which is driven by the hybridization of $\mathrm{O} 2 p$ and $\mathrm{N} 2 p$ states with Ga $3 d$ orbitals in the $\mathrm{VB}$, the top of the VB can be raised and hole mobility enhanced. The unique $\mathrm{GaO}_{\mathrm{x}} \mathrm{N}_{\mathrm{y}}$ modified nanostructured semiconductors can reduce the suppression of the electron diffusion as well as charge recombination during the PEC process. A conductive electrode composed of $\mathrm{GaO}_{\mathrm{x}} \mathrm{N}_{\mathrm{y}}$ modified semiconductor material and FTO promoted the charge separation under the applied external electric field. ${ }^{22}$ In view of the advantages of $\mathrm{GaO}_{\mathrm{x}} \mathrm{N}_{\mathrm{y}}$ and $\mathrm{TiO}_{2} \mathrm{NWs}$ described above, we explore if a nanoarchitecture composed of $\mathrm{GaO}_{\mathrm{x}} \mathrm{N}_{\mathrm{y}}$ nanocluster

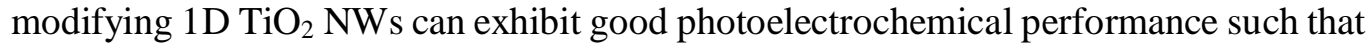
it may be later used in the oxygen evolution reaction for water splitting.

Reported methods for synthesizing $\mathrm{GaO}_{\mathrm{x}} \mathrm{N}_{\mathrm{y}}$ include hydrothermal, magnetron sputtering, chemical vapor deposition (CVD) ${ }^{23-25}$ Obviously, these methods are not only complex and tedious, but are also unable to achieve accurate control of film thickness and composition of $\mathrm{GaO}_{\mathrm{x}} \mathrm{N}_{\mathrm{y}}$. Atomic layer deposition (ALD) which is widely 
used in the semiconductor industry shows significant advantages in control of the precise film thickness and deposition for a layer-by-layer growth mechanism. ${ }^{26} \mathrm{Up}$ to now, the direct growth of $\mathrm{GaO}_{\mathrm{x}} \mathrm{N}_{\mathrm{y}}$ utilizing $\mathrm{ALD}$ has not been studied and reported.

In this paper, we developed a method to synthesize $1 \mathrm{D} \mathrm{TiO}_{2} @ \mathrm{GaO}_{\mathrm{x}} \mathrm{N}_{\mathrm{y}}$ core-shell NWs by combining hydrothermal $\mathrm{TiO}_{2} \mathrm{NW}$ synthesis together with $\mathrm{ALD}$ for $\mathrm{GaO}_{\mathrm{x}} \mathrm{N}_{\mathrm{y}}$ deposition on the NWs. This allows for the first time the precise control of the coreshell nanoarchitecture, and the influence of the resulting morphology and optical properties on the PEC performance are also investigated for the first time. The results show that a photocurrent density in $\mathrm{TiO}_{2} @ 20 \mathrm{~nm}-\mathrm{GaO}_{\mathrm{x}} \mathrm{N}_{\mathrm{y}}$ core-shell nanowires (TG20 NWs) up to $1.10 \mathrm{~mA} \mathrm{~cm}^{-2}$ is achieved. The photocurrent density value of TG20 is 14 times larger than that of $\mathrm{TiO}_{2} \mathrm{NWs}$ and the materials show high stability at this current density for 10 hours. In addition, the results of density functional theory (DFT) calculations give insight into the stability of TG NWs systems, the effect of $\mathrm{GaO}_{\mathrm{x}} \mathrm{N}_{\mathrm{y}}$ deposition on the energy gap of $\mathrm{TiO}_{2}$ and the enhanced activity towards water dissociation which is important for future work on the water splitting reaction.

\section{Experimental Section}

\section{Materials and Reagents}

Tetrabutyl titanate $\left(\mathrm{Ti}(\mathrm{OBu})_{4}, 98 \%\right)$, hydrofluoric acid ( $\mathrm{HCl}, 36-38 \%$ by weight), sodium sulfate anhydrous $\left(\mathrm{Na}_{2} \mathrm{SO}_{4}, 98 \%\right)$, ethanol $\left(\mathrm{C}_{2} \mathrm{H}_{5} \mathrm{OH}\right)$, acetone $\left(\mathrm{CH}_{3} \mathrm{COCH}_{3}\right)$, and isopropanol $\left(\mathrm{C}_{3} \mathrm{H}_{8} \mathrm{O}\right)$, were purchased from Sinopharm Chemical Reagent Co., Ltd. (Shanghai, China). Fluorine-doped tin oxide (FTO)-coated glass substrates (resistance 
$<14 \mathrm{ohm} / \mathrm{sq}$, transmittance $>90 \%$ ) were purchased from Wuhan Jinge-Solar Energy Technology Co., Ltd. (Wuhan, China). The deionized (DI) water used in the experiments was obtained from local sources. All the chemicals in the experiment were weighted by a METTLER TOLEDO ME 204 balance.

\section{Synthesis of $\mathrm{TiO}_{2} \mathrm{NWs}$}

The $\mathrm{TiO}_{2} \mathrm{NWs}$ were fabricated on FTO substrates $(2 \mathrm{~cm} \times 1 \mathrm{~cm})$ by a facile hydrothermal method. Prior to the hydrothermal process, the FTO substrates were successively cleaned in an ultrasonicator with acetone, alcohol, and DI water for 15 min, respectively. Then, they were dried with a $\mathrm{N}_{2}$ stream and placed in a reaction solution in a Teflon-lined stainless steel autoclave, with the FTO side facing up at $60^{\circ}$ against the wall. Typically, the reaction solution included $0.25 \mathrm{~mL}$ tetrabutyl titanium, $15 \mathrm{~mL}$ DI water, and $15 \mathrm{~mL}$ hydrofluoric acid. The hydrothermal reaction was maintained at $150{ }^{\circ} \mathrm{C}$. After 4 hours, the as-prepared $\mathrm{TiO}_{2} \mathrm{NWs}$ were washed with ethanol and DI water several times, and then dried for further use.

\section{Synthesis of $\mathrm{TiO}_{2} @ \mathrm{GaO}_{\mathrm{x}} \mathrm{N}_{\mathrm{y}}$ core-shell NWs}

The $\mathrm{TiO}_{2} @ \mathrm{GaO}_{\mathrm{x}} \mathrm{N}_{\mathrm{y}}$ core-shell NWs were synthesized by deposition of $\mathrm{GaO}_{\mathrm{x}} \mathrm{N}_{\mathrm{y}}$ using plasma enhanced atomic layer deposition (PE-ALD, Beneq TFS-200). For deposition of $\mathrm{GaO}_{\mathrm{x}} \mathrm{N}_{\mathrm{y}}$, the $\mathrm{TiO}_{2} \mathrm{NWs}$ were placed in the PE-ALD chamber, and trimethyl gallium (TMGa), $\mathrm{NH}_{3}$, and $\mathrm{O}_{2}$ were chosen as the typical precursors for $\mathrm{GaO}_{\mathrm{x}} \mathrm{N}_{\mathrm{y}}$ deposition. The flow ratio of $\mathrm{O}_{2}$ to $\mathrm{NH}_{3}$ was 95:5 standard cubic centimeters per minute (sccm). In our PE-ALD process, the deposition temperature is kept at $200{ }^{\circ} \mathrm{C}$ 
while the plasma power is set at $200 \mathrm{~W}$.

An ALD cycle is composed of four steps: pulse 1 - purge 1 - pulse 2 - purge 2 . Accordingly, one ALD cycle for $\mathrm{GaO}_{\mathrm{x}} \mathrm{N}_{\mathrm{y}}$ is described as follows: TMGa pulse (15 ms) - Ar purge (10 s) - ammonia plasma pulse (15 s) - Ar purge (10 s). A schematic diagram of one ALD cycle of $\mathrm{GaO}_{x} \mathrm{~N}_{\mathrm{y}}$ deposition is shown in Fig. S1. We note that $\mathrm{O}_{2}$ and $\mathrm{NH}_{3}$ are simultaneously introduced into the chamber after the plasma has been turned on. Thus, the mixture of $\mathrm{O}_{2}$ and $\mathrm{NH}_{3}$ gas reacts only with surface bound TMGa during the plasma process. By changing the number of ALD cycles, it is possible to prepare a series of $\mathrm{TiO}_{2} @ \mathrm{GaO}_{\mathrm{x}} \mathrm{N}_{\mathrm{y}}$ core-shell NWs with different thicknesses of $\mathrm{GaO}_{\mathrm{x}} \mathrm{N}_{\mathrm{y}}$. The number of PE-ALD cycles for $\mathrm{GaO}_{\mathrm{x}} \mathrm{N}_{\mathrm{y}}$ deposition ranges from 100 to 500 cycles. The thickness of $\mathrm{GaO}_{\mathrm{x}} \mathrm{N}_{\mathrm{y}}$ was estimated to be 5 (100 cycles), 10 (200 cycles), 15 (300 cycles), 20 (400 cycles), and $25 \mathrm{~nm}$ (500 cycles): the samples will be denoted as TG5, TG10, TG15, TG20, and TG25, respectively. The samples are characterized and used in PEC measurements as deposited with no post-deposition annealing. For comparison of substrates, pure $\mathrm{GaO}_{\mathrm{x}} \mathrm{N}_{\mathrm{y}}$ films of the same thickness were also grown on Si substrates at the same time in order to further study their properties.

\section{Characterization}

The crystal structure of the core-shell samples was investigated by XRD (MAC, M18XHF) using $\mathrm{Cu} \mathrm{K} \alpha$ radiation. Fourier transform infrared (FTIR) spectroscopy (Nicolet Nexus 470) and Raman spectroscopy (Spex 403 Raman microscope with 532 $\mathrm{nm}$ argon ion laser) were used to determine the chemical bonding characteristics of 
samples. The thickness and elemental composition of pure $\mathrm{GaO}_{\mathrm{x}} \mathrm{N}_{\mathrm{y}}$ thin films were measured by spectroscopic ellipsometry (SE, SOPRA, GES-5E) and glow discharge optical emission spectroscopy (GDOES, HIOKI, 200D). The morphology of the samples was exhibited using field-emission scanning electron microscopy (FESEM, Hitachi, S4800), and transmission electron microscope (TEM, Tecnai G $^{2}$ S-TWIN). A UV-Vis spectrophotometer (Cary 500, Varian Co.) was employed to characterize the optical properties. Energy dispersive X-ray (EDX) and elemental mapping images were obtained using a JEOL JEM-2100 electron microscope. Photoluminescence (PL) spectra were measured with a fluorescence spectrophotometer (Hitachi F-4500) at an excitation wavelength of $320 \mathrm{~nm}$ under ambient conditions. X-ray photoelectron spectroscopy (XPS) measurements were obtained with on a Thermo Scientific ESCA Lab 250 spectrometer that used monochromatic $\mathrm{Al} \mathrm{K \alpha}$ as the X-ray source, with a hemispherical analyzer and sample stage with multiaxial adjustability to obtain the elemental chemical states and surface composition. All the binding energies were calibrated by the $\mathrm{C} 1 \mathrm{~s}$ peak at $284.6 \mathrm{eV}$.

\section{Photoelectrochemical Measurements}

The photoelectrochemical experiments were carried out on a CHI600D electrochemical workstation (ChenHua Instruments Co. Ltd, China). In this system, the working electrode is the FTO substrates onto which the core-shell nanowires were grown, with dimensions $1 \mathrm{~cm} \times 1 \mathrm{~cm}$. A Pt plate is used as the counter electrode, and an $\mathrm{Ag} / \mathrm{AgCl}$ electrode is used as the reference electrode. The electrolyte is $0.5 \mathrm{M}$ 
$\mathrm{Na}_{2} \mathrm{SO}_{4}$ aqueous solution $(\mathrm{pH}=6.8)$. A $500 \mathrm{~W}$ Xe arc lamp (PLS-SXE 300C, Beijing Perfectlight Co., Ltd.) was used for the irradiation source to simulate sunlight (100 mW $\mathrm{cm}^{-2}$ ). The electrolyte was stirred and purged with high-purity $\mathrm{N}_{2}$ for $1 \mathrm{~h}$ before each measurement.

From the Nernst equation: $\mathrm{E}(\mathrm{RHE})=\mathrm{E}(\mathrm{Ag} / \mathrm{AgCl})+0.01976 \mathrm{~V}+0.0591 * \mathrm{pH}$, the measured potentials versus the $\mathrm{Ag} / \mathrm{AgCl}$ electrode were converted to the reversible hydrogen electrode (RHE). The scan rate of the linear sweep voltammetry (LSV) curves with light on and off were kept at $20 \mathrm{mV} \mathrm{s}^{-1}$. Time-dependent photocurrent response (It) curves were obtained with light/dark cycles of $20 \mathrm{~s}$ at an applied potential of $1.23 \mathrm{~V}$ $v s$ RHE. The electrochemical impedance spectroscopy (EIS) plots were measured in the frequency range of $10^{-1} \mathrm{~Hz}$ to $10^{5} \mathrm{~Hz}$ under an ac amplitude of $2 \mathrm{mV}$. The incident photon to current conversion efficiency (IPCE) was measured by irradiating with monochromatic light. The different wavelength of incident light (in the range of 360$470 \mathrm{~nm}$ ) were achieved by using a monochromatic filter. The IPCE values are calculated from the following equation:

$$
\operatorname{IPCE}(\%)=(1240 I) /(P \lambda)
$$

where $I$ is the measured photocurrent density at a specific wavelength, $P$ is the measured irradiance at this wavelength, and $\lambda$ is the wavelength of the incident light. ${ }^{27}$

\section{Computational Methods}

The spin-polarized DFT calculations are carried out with the VASP5.4 ${ }^{28}$ code 
using projector augmented wave (PAW) potentials ${ }^{29}$ and the Perdew-Wang (PW91) exchange correlation functional. The plane-wave energy cut-off is $400 \mathrm{eV}$ and $\mathrm{Ti}$ is described with 4 valence electrons, Ga with 13 valence electrons, $\mathrm{O}$ with 6 valance electrons, $\mathrm{N}$ with 5 valance electrons and $\mathrm{H}$ with 1 electron potential. The convergence criteria for the energy minimization and force relaxation are $10^{-4} \mathrm{eV}$ and $0.02 \mathrm{eV} / \AA$. The size of the surface supercell is such that k-point sampling is at the $\Gamma$-point and aspherical gradient corrections were applied throughout. Gaussian smearing (ISMEAR $=1)$ and $\sigma=0.1 \mathrm{eV}$ is used throughout.

A Hubbard $+\mathrm{U}$ correction $(\mathrm{DFT}+\mathrm{U})$ is used for the Ti $3 d$ states in which the value of $\mathrm{U}(\mathrm{Ti} 3 \mathrm{~d})=4.5 \mathrm{eV}$, which is consistent with previous work. ${ }^{31}$ This correction is necessary to consistently describe the partially filled Ti $3 d$-orbital that is found in reduced $\mathrm{Ti}^{3+}$ states, which can be produced by reduction of Ti-oxides. ${ }^{32}$ The computed bulk lattice parameters for rutile are $a=b=4.614 \AA$ and $c=2.962 \AA$. The model for the rutile $\mathrm{TiO}_{2}(110)$ surface consists of an 18 atomic layer slab in a $(2 \times 4)$ surface supercell expansion of rutile (110). Periodic images are separated by a vacuum gap of $15 \AA$. The Ga-oxynitirde modifier is modelled as nanoclusters of composition $\mathrm{Ga}_{6} \mathrm{O}_{5} \mathrm{~N}_{4}$ and $\mathrm{Ga}_{6} \mathrm{O}_{6} \mathrm{~N}_{3}$ and these are first relaxed in the gas phase as free clusters. We consider each $\mathrm{GaO}_{\mathrm{x}} \mathrm{N}_{\mathrm{y}}$ nanocluster adsorbed in different configurations at the rutile (110) surface and adsorption energies are computed from:

$$
E_{\text {ads }}=E_{\text {surf }+N C}-E_{\text {surf }}-E_{N C}
$$

where $E_{\text {surf }+N C}, E_{\text {surf }}$, and $E_{N C}$ are the total computed energies of the 
heterostructured of $\mathrm{TiO}_{2} @ \mathrm{GaO}_{\mathrm{x}} \mathrm{N}_{\mathrm{y}}$, the surface of rutile (110), and the gas-phase nanocluster. The $\mathrm{TiO}_{2} @ \mathrm{GaO}_{\mathrm{x}} \mathrm{N}_{\mathrm{y}}$ heterostructure is relaxed with no constraints on the structure of the nanocluster.

To model reduction of $\mathrm{TiO}_{2} @ \mathrm{GaO}_{\mathrm{x}} \mathrm{N}_{\mathrm{y}}$ we use oxygen vacancy formation in which one oxygen from the $\mathrm{GaO}_{x} \mathrm{~N}_{\mathrm{y}}$ nanocluster is removed and we computed the vacancy formation energy as follows:

$$
E_{v a c}=E\left(\mathrm{GaO}_{\mathrm{x}-1} \mathrm{~N}_{\mathrm{y}}-\mathrm{r} 110\right)-E\left(\mathrm{GaO}_{\mathrm{x}-1} \mathrm{~N}_{\mathrm{y}}-\mathrm{r} 110\right)+\frac{1}{2} E\left(\mathrm{O}_{2}\right)
$$

Where $E\left(\mathrm{GaO}_{\mathrm{x}-1} \mathrm{~N}_{\mathrm{y}}-\mathrm{r} 110\right)$ and $E\left(\mathrm{GaO}_{\mathrm{x}-1} \mathrm{~N}_{\mathrm{y}}-\mathrm{r} 110\right)$ are the total energies of the $\mathrm{TiO}_{2} @ \mathrm{GaO}_{\mathrm{x}} \mathrm{N}_{\mathrm{y}}$ heterostructured with and without an oxygen vacancy and the energy is refered to half the total energy of a free gas-phase $\mathrm{O}_{2}$ molecule computed with the same computational set-up as the surface calculations. Bader charge analysis ${ }^{33}$ and computed spin magnetisations are used to investigate oxidation states and localisation of charge. For an unmodified $\mathrm{TiO}_{2}$ rutile (110) surface the Bader charges for Ti sites are in the range 1.2-1.3 electrons, which is attributed to an oxidation state of $\mathrm{Ti}^{4+} ; \mathrm{O}^{2-}$ sites of the surface have computed Bader charges in the range 7.1-7.2 electrons. Oxygen ions of the cluster and surface are denoted $\mathrm{O}_{\mathrm{C}}$ and $\mathrm{O}_{\mathrm{S}}$, respectively, and Nitrogen in the modifier is denoted as $\mathrm{N}_{\mathrm{C}}$.

To investigate the interaction of water at $\mathrm{GaO}_{x} \mathrm{~N}_{\mathrm{y}}-\mathrm{TiO}_{2}$ heterostructures, a water molecule is adsorbed in different configurations at the $\mathrm{GaO}_{\mathrm{x}} \mathrm{N}_{\mathrm{y}}$ modifier. The adsorption energy is computed from: 


$$
E_{a d s}=E_{\text {surf }+\mathrm{H}_{2} \mathrm{O}}-E_{\text {surf }}-E_{\mathrm{H}_{2} \mathrm{O}}
$$

where $E_{\text {surf }+\mathrm{H}_{2} \mathrm{O}}, E_{\text {surf }}$ and $E_{\mathrm{H}_{2} \mathrm{O}}$ denote the energies of the $\mathrm{H}_{2} \mathrm{O}$ molecule adsorbed at the $\mathrm{GaO}_{\mathrm{x}} \mathrm{N}_{\mathrm{y}}-\mathrm{TiO}_{2}$ structure, $\mathrm{GaO}_{\mathrm{x}} \mathrm{N}_{\mathrm{y}}-\mathrm{TiO}_{2}$ and the gas phase $\mathrm{H}_{2} \mathrm{O}$ molecule, respectively.

\section{Results and discussion}

\section{Formation and characterization}

Scheme 1 presents an illustration of the $\mathrm{TiO}_{2}-\mathrm{GaO}_{\mathrm{x}} \mathrm{N}_{\mathrm{y}}$ core-shell NW (denote TG) preparation process via our two-step method. $1 \mathrm{D} \mathrm{TiO}_{2} \mathrm{NWs}$ were prepared by a hydrothermal reaction, followed by deposition of $\mathrm{GaO}_{\mathrm{x}} \mathrm{N}_{\mathrm{y}}$ on the $\mathrm{TiO}_{2} \mathrm{NW}$ sy PEALD technology, and formation of TG core-shell NWs. A series of TG core-shell NWs is obtained by varying the number of PE-ALD cycles from 100 to 500 cycles. A schematic diagram of one ALD cycle of $\mathrm{GaO}_{\mathrm{x}} \mathrm{N}_{\mathrm{y}}$ deposition is shown in Fig. S1.
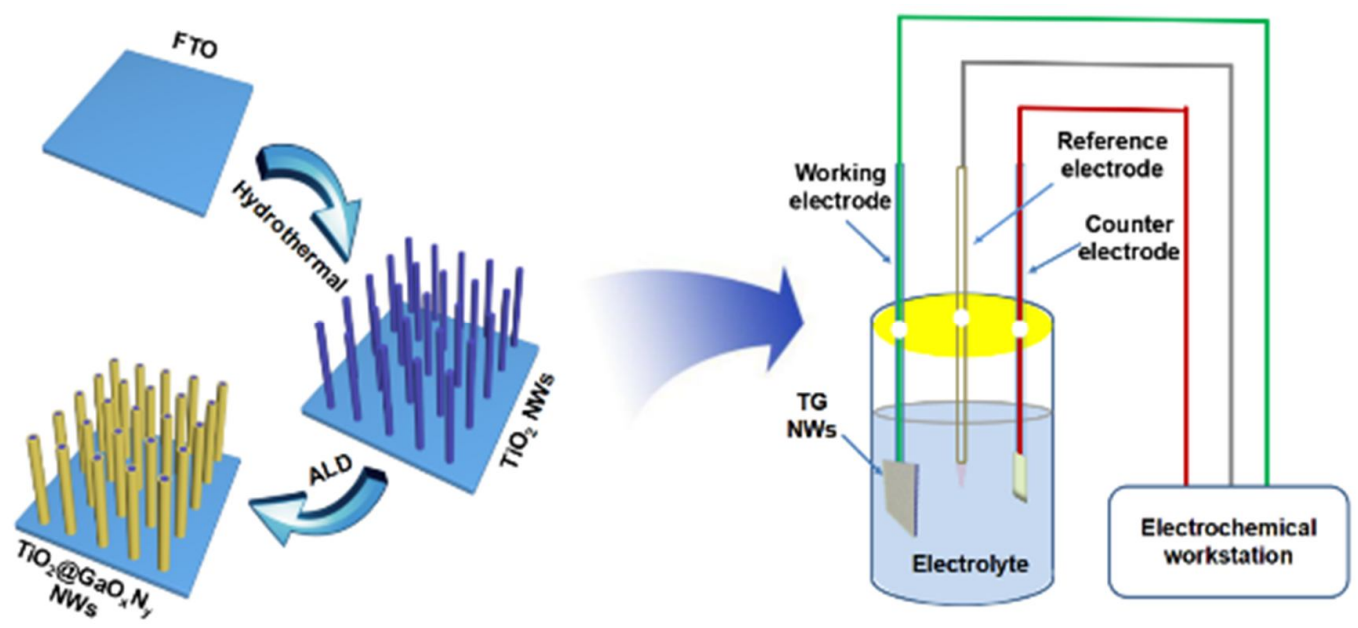

Scheme 1 Fabrication process of $\mathrm{TiO}_{2} @ \mathrm{GaO}_{\mathrm{x}} \mathrm{N}_{\mathrm{y}}$ core-shell NWs, and the PEC testing process. 
XRD measurements were used to determine the crystallographic structures of pure $\mathrm{TiO}_{2}$ and TG NWs and the diffractograms are displayed in Fig. 1(a) for FTO, $\mathrm{TiO}_{2}$, and a selection of TG nanowires. The XRD pattern for the bare FTO substrate allows for comparison of bare FTO and modified FTO. For the pure $\mathrm{TiO}_{2} \mathrm{NW}$ sample, the three main diffraction peaks centered at $2 \theta=36.953^{\circ}, 63.649^{\circ}$, and $70.721^{\circ}$ can be assigned to the (101), (002), and (112) crystal facets of rutile $\mathrm{TiO}_{2}{ }^{34} \mathrm{PDF} \# 88-1175$, with the lattice constants of $a, b=0.452 \mathrm{~nm}$ and $c=0.294 \mathrm{~nm}$. The (002) peak shows a strong and sharp feature, suggesting that the nanowires grew along the (001) direction. No other impurity phase was observed. In the TG NWs, no new peaks corresponding to $\mathrm{GaO}_{\mathrm{x}} \mathrm{N}_{\mathrm{y}}$ can be observed, while the peaks identified for rutile $\mathrm{TiO}_{2}$ persist. This is due to the fact that the low content and high dispersion of non-crystalline $\mathrm{GaO}_{\mathrm{x}} \mathrm{N}_{\mathrm{y}}$ deposited on the surface of the $\mathrm{TiO}_{2} \mathrm{NW}$ s will be amorphous and are too small to be observed with XRD. Interestingly, the (101) peak of rutile disappears at the highest loading of $\mathrm{GaO}_{\mathrm{x}} \mathrm{N}_{\mathrm{y}}, \mathrm{TG} 25$, which indicates that for thinner deposits of $\mathrm{GaO}_{\mathrm{x}} \mathrm{N}_{\mathrm{y}}$, the ALD process has only a minor influence on the phase composition and crystallinity of $\mathrm{TiO}_{2} \mathrm{NWs}$.

Raman spectra were measured to determine the phase structure. As shown in Fig. 1(b), all TG NW samples exhibit the three characteristic rutile Raman vibrational modes at $A_{1 \mathrm{~g}}\left(592 \mathrm{~cm}^{-1}\right), \mathrm{E}_{\mathrm{g}}\left(427 \mathrm{~cm}^{-1}\right)$ and $\mathrm{E}_{2 \mathrm{H}}\left(217 \mathrm{~cm}^{-1}\right) .{ }^{35}$ Although the peak intensity and sharpness of these peaks related to the Raman vibrations of rutile $\mathrm{TiO}_{2}$ increases as the thickness of $\mathrm{GaO}_{\mathrm{x}} \mathrm{N}_{\mathrm{y}}$ increases, no Raman peaks characteristic of $\mathrm{GaO}_{\mathrm{x}} \mathrm{N}_{\mathrm{y}}$ or characteristic of significant structural modifications to the $\mathrm{TiO}_{2} \mathrm{NWs}$ are present, which 
is in agreement with XRD results reported above.

FTIR spectra were also recorded to demonstrate the effect of the GaON coating on the IR active vibrational modes of $\mathrm{TiO}_{2} \mathrm{NWs}$ with the different $\mathrm{GaO}_{\mathrm{x}} \mathrm{N}_{\mathrm{y}}$ thicknesses; these are shown in Fig. 1(c). The FTIR spectrum of the pure $\mathrm{TiO}_{2} \mathrm{NWs}$ is very similar to that of $\mathrm{TiO}_{2} \mathrm{NWs}$ as previously reported. ${ }^{36}$ The absorption peaks at 523, 670, and $1162 \mathrm{~cm}^{-1}$ are the characteristic vibrations of the Ti-O-Ti networks in $\mathrm{TiO}_{2}$. After deposition of $\mathrm{GaO}_{x} \mathrm{~N}_{y}$, the vibrational peaks characteristic of $\mathrm{GaO}_{\mathrm{x}} \mathrm{N}_{\mathrm{y}}$ appeared in $\mathrm{TG}$ NWs. The absorption peaks at 778,877 , and $1029 \mathrm{~cm}^{-1}$ are related to the typical stretching modes of aromatic Ga-O-N as described in the literature. ${ }^{21}$ The data in ref. ${ }^{21}$ are for $\mathrm{GaON}-\mathrm{ZnO}$, with peaks at $690,811,921$ and $1025 \mathrm{~cm}^{-1}$. There is good correspondence between the peaks at $1029 / 1025,921 / 877$ and $778 / 811 \mathrm{~cm}^{-1}$, with any differences arising from the different interactions and interface structures between $\mathrm{GaON}$ and $\mathrm{ZnO} / \mathrm{TiO}_{2}$. The peak at $669 \mathrm{~cm}^{-1}$ is due to $\mathrm{Ga}-\mathrm{O}$ vibrations of $\mathrm{Ga}_{2} \mathrm{O}_{3} .{ }^{37}$ Moreover, the lack of Ti-O-Ti stretching vibrations at $1162 \mathrm{~cm}^{-1}$ implies full coverage of $\mathrm{GaO}_{x} \mathrm{~N}_{\mathrm{y}}$ over $\mathrm{TiO}_{2} \mathrm{NWs}$. The existence of $\mathrm{GaO}_{\mathrm{x}} \mathrm{N}_{\mathrm{y}}$ on $\mathrm{TiO}_{2} \mathrm{NWs}$ can be therefore confirmed on the basis of FTIR spectra, which will be further confirmed with depth profiling and microscopy observations discussed below.

To determine the thickness, change in composition with depth, and the distribution and uniformity of $\mathrm{Ga}, \mathrm{O} \mathrm{N}$ and $\mathrm{Ti}$, a typical $\mathrm{GaO}_{\mathrm{x}} \mathrm{N}_{\mathrm{y}}$ with 200 PE-ALD cycles deposited on a $\mathrm{Si}$ substrate was characterized by spectroscopic ellipsometry (SE) and glow discharge optical emission spectroscopy (GDOES). From the SE results, the thickness 
of $\mathrm{GaO}_{\mathrm{x}} \mathrm{N}_{\mathrm{y}}$ after 200 cycles of deposition is $10 \mathrm{~nm}$, the refractive index value (n) is 1.740 , and the extinction coefficient $(\mathrm{k})$ is $6.51 \times 10^{-3}$ at a wavelength of $632.8 \mathrm{~nm}$. The SE data both measured and fitted and optical constants are shown in Fig. S2(a) and (b).

The GDOES depth profiles for a 10nm GaON film are shown in Fig. 1(d). The time needed for complete etching of the $\mathrm{GaO}_{\mathrm{x}} \mathrm{N}_{\mathrm{y}}$ is 2.5 s. Overall, a homogeneous elemental distribution of $\mathrm{Ga}, \mathrm{O}$, and $\mathrm{N}$ was detected in the sample. From the GDOES analysis of elements, the highest intensity in $\mathrm{GaO}_{\mathrm{x}} \mathrm{N}_{\mathrm{y}}$ sample was for the Ga signal, with decreased intensity for the $\mathrm{N}$ signal, and the lowest intensity for the $\mathrm{O}$ signal. The relatively large amount of $\mathrm{N}$ and $\mathrm{O}$ in $\mathrm{GaO}_{\mathrm{x}} \mathrm{N}_{\mathrm{y}}$ film in this work in PEALD grown $\mathrm{GaO}_{\mathrm{x}} \mathrm{N}_{\mathrm{y}}$ offers advantages when compared to traditional film deposition technologies such as hydrothermal method, CVD, and ALD. Similar phenomena were also investigated during the growth of $\mathrm{AlON}$ films in our previous report, ${ }^{38}$ which are more conducive for fabrication and applications in the field of electronic devices and catalysts. 

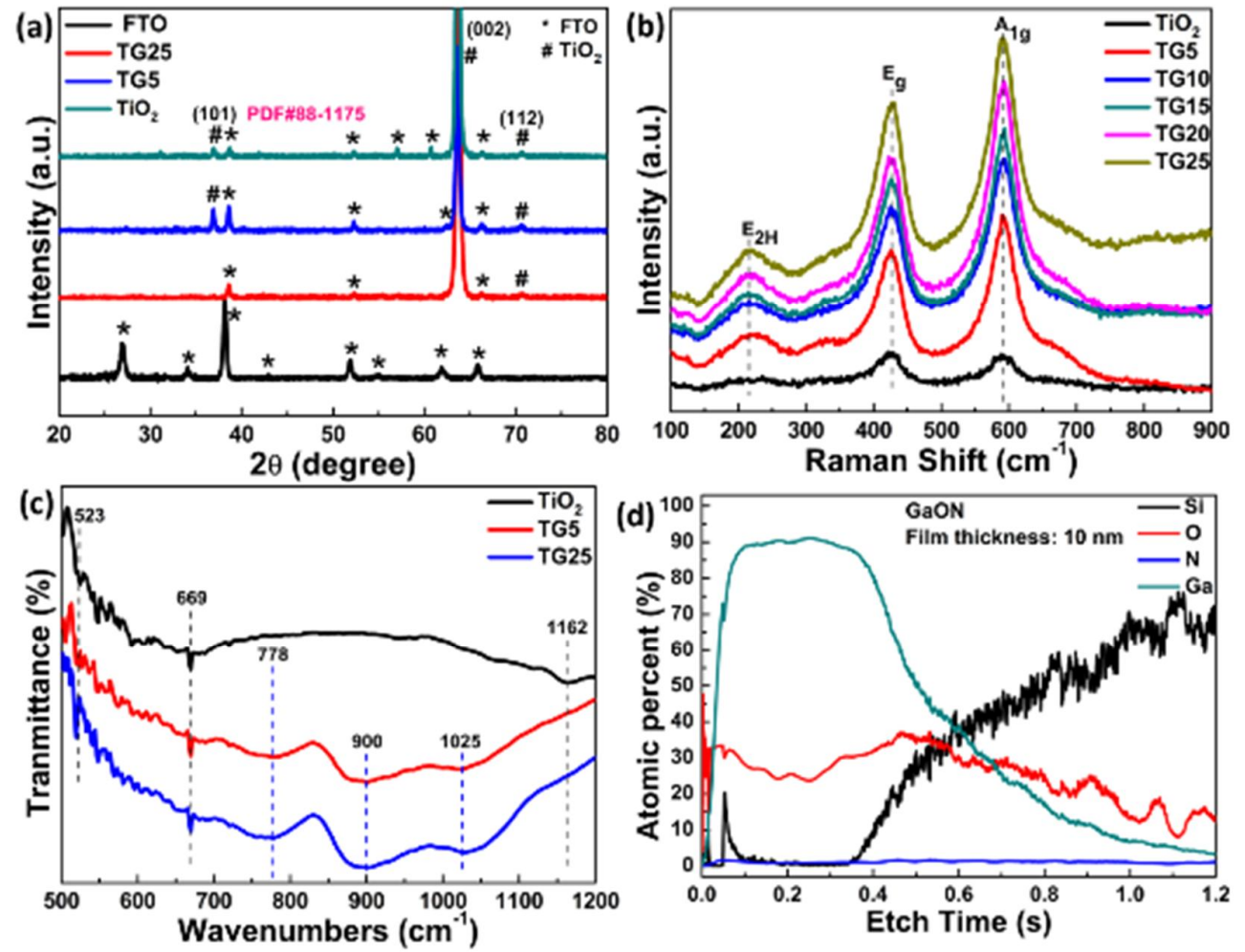

Fig.1 (a) XRD patterns, (b) Raman spectra, and (c) FTIR spectra of pure $\mathrm{TiO}_{2} \mathrm{NWs}$ and TG NWs. (d) The GDOES depth profile is shown for elemental Ga, O, and $\mathrm{N}$ elements for representative $\mathrm{GaO}_{x} \mathrm{~N}_{\mathrm{y}}$ film with thickness of $10 \mathrm{~nm}$ deposited on the Si substrate.

SEM images of the FTO glass substrate, pure $\mathrm{TiO}_{2} \mathrm{NWs}$ from hydrothermal synthesis, and a TG10 core-shell nanowires sample are shown in Figure 2(a)-(c). Fig. 2(a) shows that the conductive FTO surface was covered by columnar grains. After hydrothermal NW synthesis, the FTO surface was covered by $\mathrm{TiO}_{2} \mathrm{NWs}$, which are shown in Fig. 2(b). The $\mathrm{TiO}_{2} \mathrm{NWs}$ are tetragonal with a square facet on the top and the average diameter and length are approximately $20 \mathrm{~nm}$ and $1 \mu \mathrm{m}$, respectively. Additionally, the top facets of the $\mathrm{TiO}_{2} \mathrm{NWs}$ contain many step edges (the inset of Fig. 
2(b)), which are sites for further growth of the NWs. The side facets are smooth, and as a result, growth at the side is disfavored. Therefore, the $\mathrm{TiO}_{2} \mathrm{NWs}$ provide abundant highly accessible interfaces for the PE-ALD process of the $\mathrm{GaO}_{\mathrm{x}} \mathrm{N}_{\mathrm{y}}$ shell. After the deposition of the $\mathrm{GaO}_{\mathrm{x}} \mathrm{N}_{\mathrm{y}}$ shell layer from 200 PE-ALD cycles (Fig. 2c), the TG coreshell structure still maintains the $\mathrm{TiO}_{2} \mathrm{NW}$ structure, but the surfaces became more obviously rough along the entire length. Notably, the top of TG core-shell NWs change shape from tetragonal to circular, as shown in the inset of Fig. 2(c). High crystal surface energy and roughness of (001) facet are more favorable for $\mathrm{GaO}_{\mathrm{x}} \mathrm{N}_{\mathrm{y}}$ deposition and nucleation, as seen in the Fig. 2(b) and (c). In addition, the aspect ratio of (110) facet also provides favorable conditions for uniform deposition of $\mathrm{GaO}_{\mathrm{x}} \mathrm{N}_{\mathrm{y}}$, which is consistent with our previous reports ${ }^{21,39}$. When we run $100,200,300,400$ and 500 cycles PE-ALD cycles, the thicknesses of $\mathrm{GaO}_{\mathrm{x}} \mathrm{N}_{\mathrm{y}}$ samples measured from SE are 4.97, 9.12, $14.41,18.49$, and $26.71 \mathrm{~nm}$, respectively. The apparent thickness is therefore linear with the number of PE-ALD cycles. On the contrary, compared to ALD technique, the traditional deposition techniques for synthesizing $\mathrm{GaO}_{\mathrm{x}} \mathrm{N}_{\mathrm{y}}$ include hydrothermal and chemical methods which show some disadvantages in the precise control of morphology and composition of $\mathrm{GaO}_{\mathrm{x}} \mathrm{N}_{\mathrm{y}}$. Patil et al. prepared the ternary heterostructure $\mathrm{GaN} / \mathrm{ZnO} / \mathrm{MWCNTs}$ by using metal organic chemical vapour deposition techniques, which cannot precisely control the composition of $\mathrm{GaN}^{19}$. Khan et al. fabricated the $\mathrm{GaON} / \mathrm{ZnO}$ nanoarchitectures with uncontrolled morphologies by the hydrothermal method ${ }^{21}$. Hu et al. reported the synthesis of wurtzite-like GaON photocatalysts by the nitridation of $\mathrm{Ga}(\mathrm{OH})_{3}$ with $\mathrm{NH}_{3}$ in a temperatures range between 
550 and $900{ }^{\circ} \mathrm{C}$, in which the morphologies and components of $\mathrm{GaON}$ film cannot be regulated accordingly $\mathrm{y}^{25}$. Therefore, we show that by simply varying the number of ALD cycles, the thickness of the $\mathrm{GaO}_{\mathrm{x}} \mathrm{N}_{\mathrm{y}}$ shell can be precisely tuned, in contrast to these other, less controlled approaches, which we later show can be used to tune the photoelectrochemical properties of the $\mathrm{TiO}_{2}$ NWs.

TEM and HRTEM were further carried out to confirm the morphologies of the pure $\mathrm{TiO}_{2}$ and the TG core-shell structures. As shown in Fig. 2(d), the TEM image of a single nanowire in a representative TG10 sample reveals that $\mathrm{GaO}_{\mathrm{x}} \mathrm{N}_{\mathrm{y}}$ covers the entire 1D $\mathrm{TiO}_{2} \mathrm{NW}$, which is consistent with our previous reported for the $\mathrm{ZnO}-\mathrm{GaON}$ systems ${ }^{18}$. Obviously, $\mathrm{TiO}_{2} \mathrm{NW}$ with a diameter of $22 \mathrm{~nm}$ was covered by an $8-\mathrm{nm}$ thin shell of $\mathrm{GaO}_{\mathrm{x}} \mathrm{N}_{\mathrm{y}}$, in line with the SEM results in Fig. 2(c). The large and intimate interfacial contact between the core and the thin shell promotes the formation of a heterojunction between the $\mathrm{TiO}_{2}$ and $\mathrm{GaO}_{\mathrm{x}} \mathrm{N}_{\mathrm{y}}$, which results in an enhanced transfer and separation of photogenerated charge carriers, thereby improving the photoelectrochemical activity as we will discuss later. The HRTEM image of TG10 in Fig. 2(e) reveals that two different fringes exist in the TG core-shell NWs. For the selected area in Figure 2(f), marked by the red frame, the lattice fringes with interplanar spacing of $0.32 \mathrm{~nm}$ are assigned to the d-spacing of the (112) crystallographic planes of rutile. ${ }^{40}$ The $\mathrm{TiO}_{2}$ growth direction of NWs was observed in the $<001>$ direction, which is in accordance with XRD results indicating that the intensity of the (002) diffraction peak is stronger than that of the (101) peak. The HRTEM image of the $\mathrm{GaO}_{\mathrm{x}} \mathrm{N}_{\mathrm{y}}$ shell, 
as shown in Fig. 2(e), indicates poor crystallinity. In Fig. 2(g) and (h), two lattice spacing can be clearly identified with interplanar distances of 0.28 and $0.26 \mathrm{~nm}$. These would be consistent with the interplanar distances of the (100) and (002) planes of GaN. However, no evidence for crystallization of $\mathrm{Ga}_{2} \mathrm{O}_{3}$ or $\mathrm{GaON}$ was found, which suggests that the $\mathrm{GaO}_{\mathrm{x}} \mathrm{N}_{\mathrm{y}}$ shell may contain some possible mixture of crystalline $\mathrm{GaN}$ and amorphous $\mathrm{Ga}_{2} \mathrm{O}_{3}$ or $\mathrm{GaON}$. Furthermore, the SAED (Selected area electron diffraction) pattern for TG10 (inset of Fig. 2(d)) can be indexed with the (001) and (210) planes of rutile $\mathrm{TiO}_{2}$ and suggest that $\mathrm{TG} 10$ contains a $\mathrm{GaO}_{\mathrm{x}} \mathrm{N}_{\mathrm{y}}$ shell. It is worth emphasizing that the content of crystalline $\mathrm{GaN}$ in $\mathrm{GaON}$ is very small, and the $\mathrm{GaON}$ modifiers are dominated by amorphous $\mathrm{Ga}_{2} \mathrm{O}_{3}$ and $\mathrm{GaON}$ (Fig. S3). Similar crystallization properties and phenomena have been observed during the growth of other complex metal oxides by ALD technology. ${ }^{41}$

The HAADF (High-angle annular dark field) image of a single TG core-shell NW in Fig. 2(i) demonstrates that the $\mathrm{GaO}_{x} \mathrm{~N}_{y}$ shell is brighter than the $\mathrm{TiO}_{2}$ core. This arises from the mass contrast difference between the $\mathrm{TiO}_{2}$ core and $\mathrm{GaO}_{\mathrm{x}} \mathrm{N}_{\mathrm{y}}$ shell. Additionally, the line scanning results also demonstrate the distribution and configuration of $\mathrm{Ga}, \mathrm{Ti}, \mathrm{O}$, and $\mathrm{N}$, as shown in Fig. 2(j)-(m). Ti, O, and $\mathrm{N}$ are contained in the NW core, while $\mathrm{Ga}, \mathrm{O}$, and $\mathrm{N}$ are found in the shell. We note that the existence of elemental $\mathrm{N}$ in the core may be due to the Kirkendall effect. ${ }^{42}$ These results indicate successful growth of a uniform $\mathrm{GaO}_{x} \mathrm{~N}_{\mathrm{y}}$ shell on the $\mathrm{TiO}_{2} \mathrm{NWs}$. 


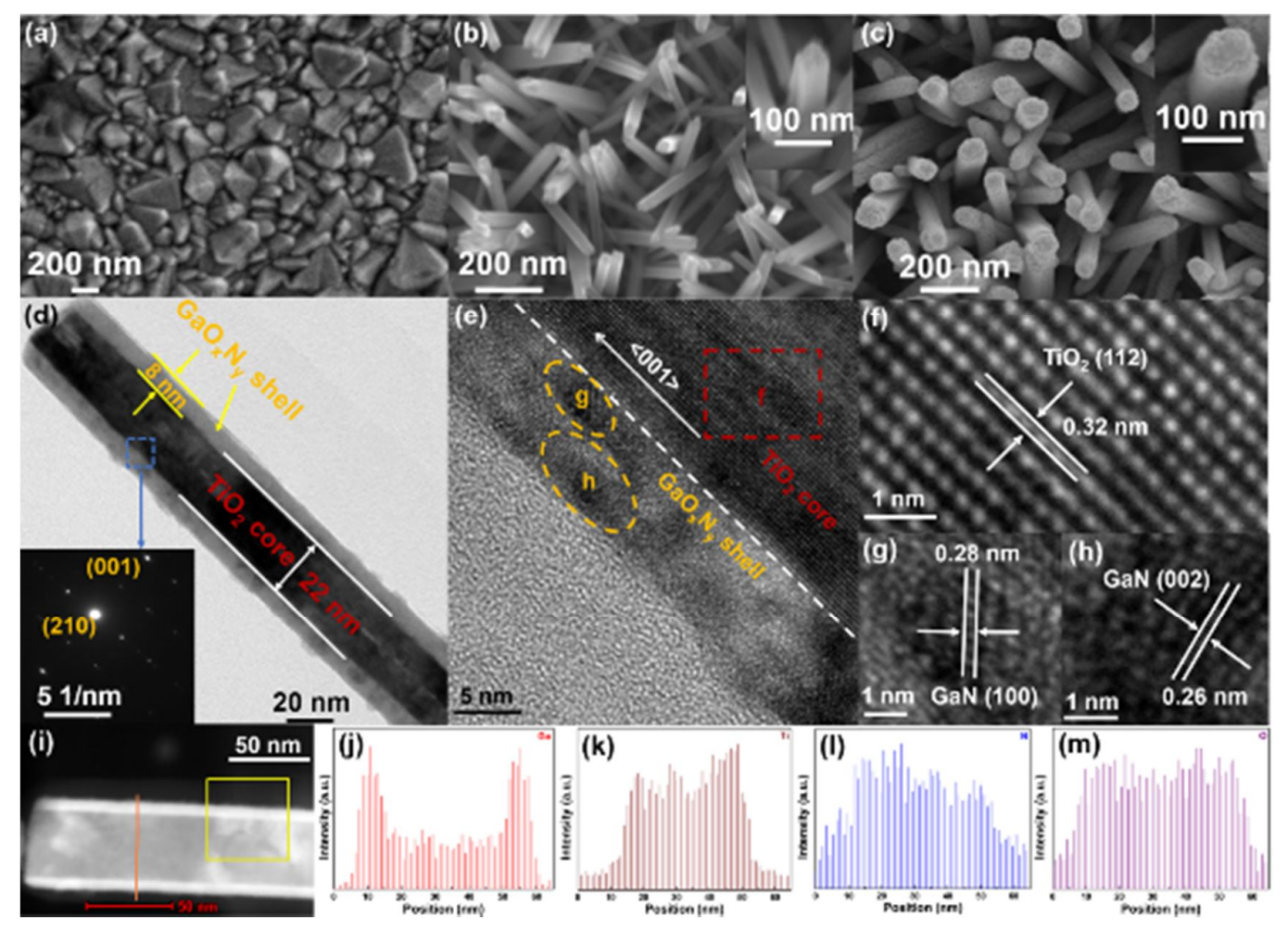

Fig.2 SEM images of (a) the FTO glass substrate, (b) pure $\mathrm{TiO}_{2} \mathrm{NWs}$, and (c) TG10. Insets in (b) and (c) show the bottom view of $\mathrm{TiO}_{2}$ and TG10. TEM image of (d) TG10, (e) HRTEM image of TG10 and (f) - (h) the designated $\mathrm{f}-\mathrm{h}$ parts in Fig. 2(e). Inset in (d) shows the corresponding SAED pattern. (i) HAADF image of a single TG10 NW, and (j)-(m) line-scanning profiles of the elements $\mathrm{Ga}, \mathrm{Ti}, \mathrm{N}$, and $\mathrm{O}$ across the TG10 nanowire (red line in the HAADF).

Given the limited penetration depth of the X-rays ( $c a .10 \mathrm{~nm}$ ) we use a representative thin TG5 sample for XPS analysis. The XPS spectra are shown in Fig. 3. The XPS survey spectra in Fig. S4 contain peaks for Ga 2p, O 1s, Ti 2p, N 1s, Ga 3s, Ga 3p, and $\mathrm{Ga} 2 \mathrm{~d}$, indicating the existence of $\mathrm{N}$ and $\mathrm{Ga}$ in the TG5 sample. This confirms the deposition of $\mathrm{GaO}_{x} \mathrm{~N}_{\mathrm{y}}$ on the surface of $\mathrm{TiO}_{2} \mathrm{NWs}$. 
As shown in Fig. 3(a), the high-resolution spectrum of $\mathrm{N} 1 \mathrm{~s}$ can be deconvoluted into two peaks. The peaks at 397.0 and $399.9 \mathrm{eV}$ can be assigned to the $\mathrm{Ga}-\mathrm{N}$ and $\mathrm{Ga}-$ O-N binding energies in GaN and GaON, respectively. ${ }^{43}$ No other $\mathrm{N}$ chemical bonds, such as in $\mathrm{NO}_{2}$ nitrite $(404.5 \mathrm{eV})$ and $\mathrm{NO}_{3}$ nitrate $(406.8 \mathrm{eV})$ were observed, which reveal the high quality of the $\mathrm{GaO}_{\mathrm{x}} \mathrm{N}_{\mathrm{y}}$ shells. It is important to note that doping $\mathrm{N}$ into metal oxides has always been a challenge, but this problem was resolved in our PEALD process. We estimate that $6.2 \% \mathrm{~N}$ is present from the XPS spectrum of TG5. Even with a relatively few PE-ALD cycles and a low $\mathrm{NH}_{3}$ flow ratio $(5 \mathrm{sccm})$, the $\mathrm{GaO}_{\mathrm{x}} \mathrm{N}_{\mathrm{y}}$ shell shows significant atomic percentages of $\mathrm{N}$. Having TG samples with a high $\mathrm{N}$ content is beneficial in enhancing the visible-light absorbance and photoelectrochemical performance as the $\mathrm{N} 2 \mathrm{p}$ states tend to shift the valance band edge to higher energy. ${ }^{44}$

In Fig. 3(b), the $\mathrm{O} 1 \mathrm{~s}$ peaks consist of three components, corresponding to Ti-O (530.4 eV), Ga-O $(530.7 \mathrm{eV})$, and Ga-O-N $(532.4 \mathrm{eV}),{ }^{45}$ suggesting the formation of a $\mathrm{GaO}_{\mathrm{x}} \mathrm{N}_{\mathrm{y}}$ shell structure. The Ti $2 \mathrm{p}$ spectrum in Fig. 3(c) features two characteristic peaks at 457.9 and $463.6 \mathrm{eV}$, which correspond to $2 \mathrm{p}_{3 / 2}$ and $2 \mathrm{p}_{1 / 2}$, respectively. These peaks indicate that the presence of $\mathrm{Ti}^{4+}$ state in TG core-shell NWs, thus the oxidation state of Ti remains unchanged upon modification with $\mathrm{GaO}_{x} \mathrm{~N}_{y}$ by PE-ALD. Fig. 3(d) manifests Ga 2p spectrum, in which two peaks at 1144.5 and $1117.6 \mathrm{eV}$ are assigned to the $2 \mathrm{p}_{1 / 2}$ and $2 \mathrm{p}_{3 / 2}$, respectively, and this is associated with $\mathrm{Ga}^{3+}$ cation oxidation state. The energy spacing between $2 \mathrm{p}_{1 / 2}$ and $2 \mathrm{p}_{3 / 2}$ was $26.9 \mathrm{eV}$, which is in agreement with 
our previous reports for $\mathrm{Ga} 2 \mathrm{p}$ in $\mathrm{GaZnO}$ materials. ${ }^{41}$

Fig. 3(e) and (f) show high-resolution XPS spectra of Ga 2 $\mathrm{p}_{3 / 2}$ and Ga $3 \mathrm{~d}$ from the TG 5 sample. The peaks at 1118.1 and $1117.3 \mathrm{eV}$ are, respectively, assigned to the Ga$\mathrm{O}$ and Ga-N bonds, and the peaks at 22.4 and $20.1 \mathrm{eV}$, respectively, belong to the Ga$\mathrm{O}$ and Ga-N bonds, further demonstrating the existence of $\mathrm{Ga}_{2} \mathrm{O}_{3}$ and $\mathrm{GaN} .^{46}$

Fig. S4 shows the XPS spectra for pure $\mathrm{TiO}_{2}$. Upon comparing the XPS signals of $\mathrm{O}$ 1s and $\mathrm{Ti} 2 \mathrm{p}$ between $\mathrm{TiO} 2$ and TG5, we found that the disappearance of $\mathrm{O}-\mathrm{H}$ bonds and slight red shift of Ti 2p. The disappearance of O-H bonds in TG5 is due to the epitaxial growth process of $\mathrm{GaO}_{x} \mathrm{~N}_{\mathrm{y}}$ onto the external surface of the $\mathrm{TiO}_{2}$. This can be proved by the small mismatch lattices between $\mathrm{TiO}_{2}(0.32 \mathrm{~nm}$ of the (112) plane) and $\mathrm{GaO}_{\mathrm{x}} \mathrm{N}_{\mathrm{y}}(0.28 \mathrm{~nm} 0.26 \mathrm{~nm} \text { of (100) and (002) planes) })^{18}$, which provides the condition for the growth of crystalline $\mathrm{GaO}_{\mathrm{x}} \mathrm{N}_{\mathrm{y}}$ even at the low ALD deposition temperature of $200{ }^{\circ} \mathrm{C}$, as shown in Fig.2(e)-(g). Furthermore, the TEM results also indicated that the coated $\mathrm{GaON}$ shell close contact with $\mathrm{TiO}_{2}$ presented high crystallinity, while other layer was amorphous. The interface between crystal and amorphous in TG system benefits the effective electron hole separation and transmission and separation, enhancing the PEC performance [REFERENCES]. The slight red shift of Ti $2 p$ may mainly attributed to the effect of hybridization of $\mathrm{O} 2 \mathrm{p}$ and $\mathrm{N} 2 \mathrm{p}$ states with $\mathrm{Ga} 3 \mathrm{~d}$ $\operatorname{orbitals}^{15}$, which promotes higher electron mobility to enhance the PEC performance, as we explained before. 

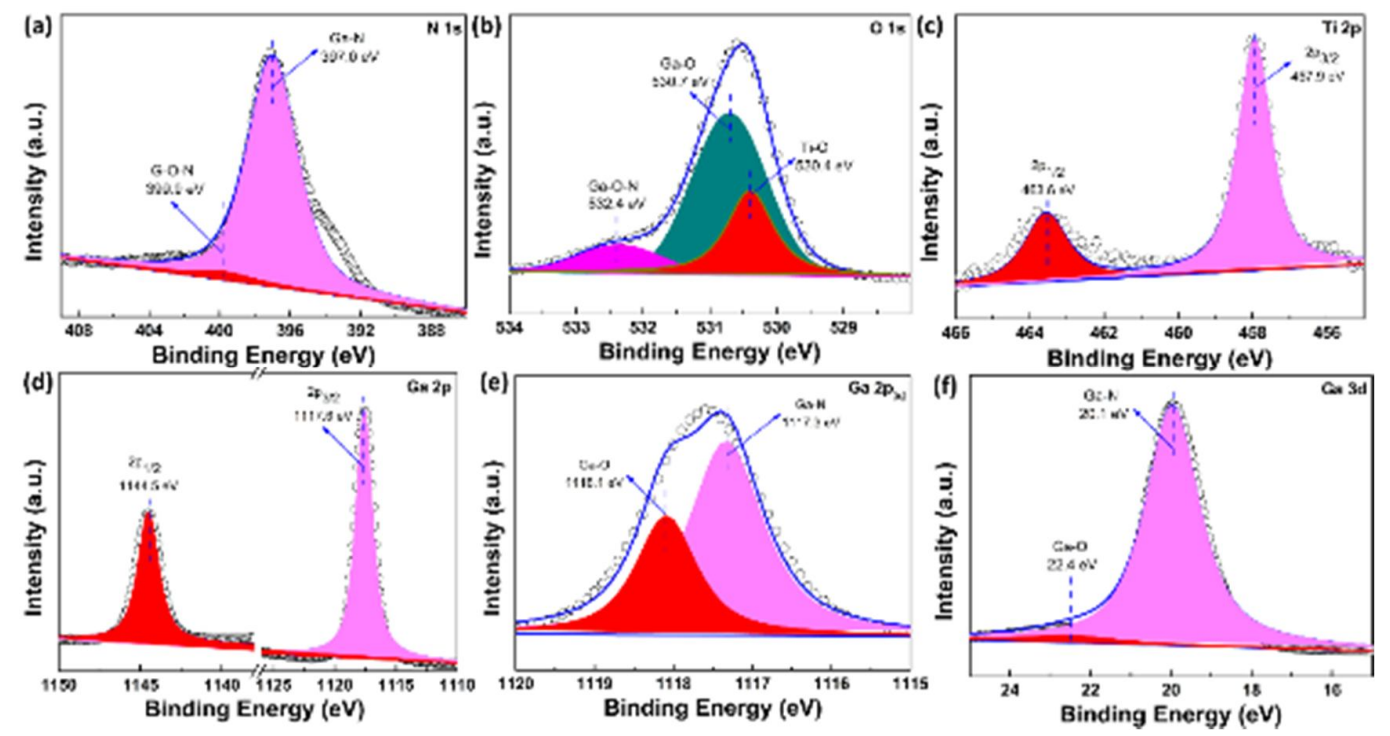

Fig.3 XPS spectra of the TG5 sample: (a) N 1s, (b) O 1s, (c) Ti 2p, (d) Ga 2p, (e) Ga $2 \mathrm{p}_{3 / 2}$, (f) Ga $3 \mathrm{~d}$.

The UV-Vis diffuse reflectance spectra (DRS) are presented in Fig. 4(a). For unmodified $\mathrm{TiO}_{2} \mathrm{NWs}$, the significant absorption at wavelengths shorter than $366 \mathrm{~nm}$ in the UV is due to the intrinsic band gap absorption. ${ }^{47,48}$ It is obvious that loading the $\mathrm{GaO}_{\mathrm{x}} \mathrm{N}_{\mathrm{y}}$ onto the surface of $\mathrm{TiO}_{2} \mathrm{NWs}$ can broaden light absorption towards the visible light region. In addition, it appears that the absorption of light by the TG core-shell NWs is enhanced compared to unmodified $\mathrm{TiO}_{2} \mathrm{NWs}$. The absorption edge of TG NWs also displays a red shift with an increase in the $\mathrm{GaO}_{\mathrm{x}} \mathrm{N}_{\mathrm{y}}$ thickness. More importantly, the TG20 sample shows enhanced light absorption when compared to unmodified $\mathrm{TiO}_{2}$ and other TG NWs, which reveals that the $\mathrm{GaO}_{\mathrm{x}} \mathrm{N}_{\mathrm{y}}$ layer plays an important role in utilizing sunlight and that there is an optimum thickness of the $\mathrm{GaO}_{\mathrm{x}} \mathrm{N}_{\mathrm{y}}$ shell. There is a small characteristic peak at $465 \mathrm{~nm}$ in the TG25 sample, which is likely due to a small amount of $\mathrm{GaO}_{\mathrm{x}} \mathrm{N}_{\mathrm{y}}{ }^{23}$ The energy band gap $\left(\mathrm{E}_{\mathrm{g}}\right)$ is estimated from the conventional Tauc 
equation:

$$
(\alpha h v)^{2}=A\left(h v-E_{g}\right)
$$

where $\alpha$ denotes the absorption coefficient, $h$ denotes Planck's constant, $v$ denotes the frequency of the incident photon, and A denotes a constant that depends on the electron or hole mobility. ${ }^{49}$ The corresponding Kubelka-Munk-transformed reflectance spectra are exhibited in Figure 4(b). The calculated $E_{g}$ from Fig. 4(b) is estimated to be 3.20 $\mathrm{eV}$ for pure $\mathrm{TiO}_{2} \mathrm{NWs}$ and $2.15 \mathrm{eV}$ for TG25 NWs, indicating that the presence of $\mathrm{GaO}_{\mathrm{x}} \mathrm{N}_{\mathrm{y}}$ strongly enhances light absorption in the visible region, which makes this heterostructured material suitable for visible light photoelectrochemical water splitting.

Fig. 4(c) shows that the direct gap transition energies of samples TG5 to TG25 were approximately $3.10,3.02,2.91,2.58$, and $2.15 \mathrm{eV}$. As implied in Figure 4(c), the nitride and oxide of gallium, $\mathrm{GaN}$ and $\mathrm{Ga}_{2} \mathrm{O}_{3}$ have band gap energies of 3.4 and $4.7 \mathrm{eV}$, respectively, ${ }^{50}$ and can only absorb UV light. The variation in the TG band gap with changing $\mathrm{GaO}_{\mathrm{x}} \mathrm{N}_{\mathrm{y}}$ thickness is therefore not driven by formation of bulk gallium oxides or nitrides, but is instead associated with the mixed oxygen and nitrogen compositions in $\mathrm{GaO}_{\mathrm{x}} \mathrm{N}_{\mathrm{y}}$, and the formation of the heterojunction with the $\mathrm{TiO}_{2} \mathrm{NWs}$ which leads to a reduction in the band gap over unmodified $\mathrm{TiO}_{2}$. TG25 has the smallest band gap, probably due to the highest nitrogen and oxygen content, which would cause a high degree of $\mathrm{O}_{2 p}$ with $\mathrm{N}_{2 p}$ orbital hybridization and shift the valence band maximum upwards via $\mathrm{p}$-d repulsion as previously described. ${ }^{25,51,52}$ 
The TG25 sample shows a weaker light absorption than that of TG20 (>600 nm) in Fig.4a. It is proposed that the additional thick $\mathrm{GaON}$ shells $\left(25 \mathrm{~nm}-\mathrm{GaO}_{\mathrm{x}} \mathrm{N}_{\mathrm{y}}\right)$ are now sufficiently thick that absorption is dominated by $\mathrm{GaON}$ rather than the $\mathrm{GaON}-\mathrm{TiO} 2$, together with a decrease in the surface area of the $1 \mathrm{D} \mathrm{TiO}_{2}$ nanostructures which inhibits light absorption. As shown in Fig.4a, the $\mathrm{GaO}_{\mathrm{x}} \mathrm{N}_{\mathrm{y}}$ film shows a decreasing absorption trend after the wavelength of $600 \mathrm{~nm}$ compared with $\mathrm{TiO}_{2}$ and $\mathrm{TG}$ samples. Similarly, Khan et al. ${ }^{4}$ also reported that the $\mathrm{GaON}$ shows a weaker light absorption than $\mathrm{ZnO}$ $\mathrm{GaON}$ system with the increasing of the wavelength.

The carrier recombination, migration, capture, and separation of the photogenerated $\mathrm{e}^{-}-\mathrm{h}^{+}$pairs were studied by PL spectrometry. Fig. 4(d) shows the spectra of $\mathrm{TiO}_{2}$ and TG NWs. Under an excitation wavelength of $320 \mathrm{~nm}$, the typical broad emission band from $380 \mathrm{~nm}$ to $580 \mathrm{~nm}$ for rutile $\mathrm{TiO}_{2}$ is observed. All samples show three characteristic peaks around 385, 420, and $466 \mathrm{~nm}$, which can be attributed to the intrinsic emission of rutile $\mathrm{TiO}_{2}$ and the band edge free excitons. ${ }^{53}$ There are no new PL features present in the modified TG NWs. The intensity of the PL spectrum for TG $\mathrm{NWs}$ is much reduced compared to the pure $\mathrm{TiO}_{2} \mathrm{NWs} .{ }^{54,55}$ In addition, as the thickness of the $\mathrm{GaO}_{\mathrm{x}} \mathrm{N}_{\mathrm{y}}$ layer increases, the emission intensity decreases down to the first minimum in sample TG20, and then increases in sample TG25. The lower PL intensity of TG20 implies that the modification with $\mathrm{GaO}_{\mathrm{x}} \mathrm{N}_{\mathrm{y}}$ impedes the recombination of $\mathrm{e}^{-}$ and $\mathrm{h}^{+}$, which is clearly beneficial to the photocatalytic performance. ${ }^{56}$ Based on the analysis above, we speculate that the TG20 should exhibit the best 
photoelectrochemical performance of our samples, which is discussed below.
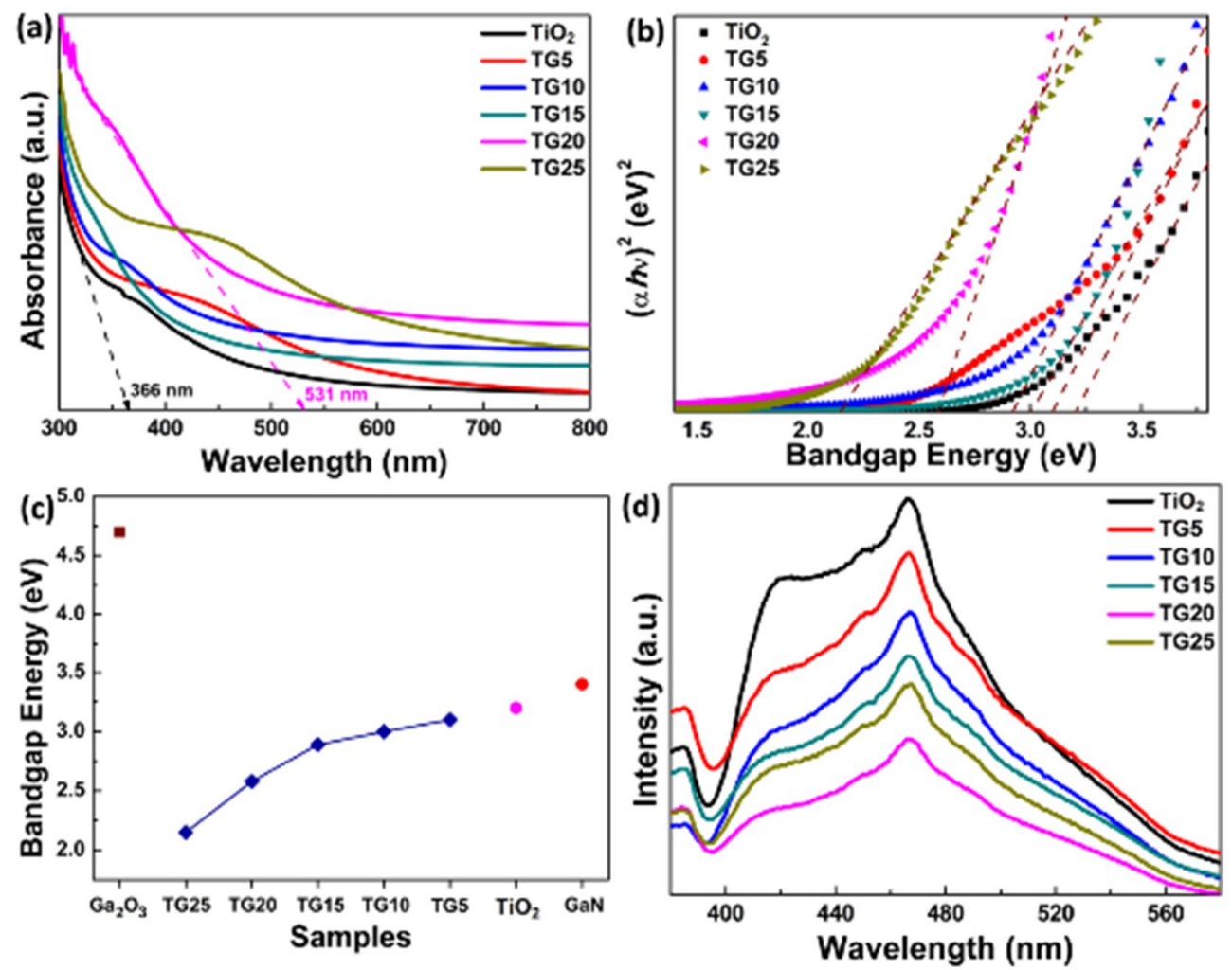

Fig.4 (a) Diffuse reflectance spectra of the $\mathrm{TiO}_{2}$ NWs and different TG NWs, (b) plots of $(\alpha h v)^{2}$ versus bandgap energy for direct gap transition of the $\mathrm{TiO}_{2} \mathrm{NWs}$ and different TG NWs, (c) band gap energy of the $\mathrm{TiO}_{2}$ NWs and different TG NWs. The band gap energies of $\mathrm{Ga}_{2} \mathrm{O}_{3}$ and $\mathrm{GaN}$ are also provide in panel (c). (d) PL spectra of the $\mathrm{TiO}_{2}$ NWs and different TG NWs.

\section{Photoelectrochemical performance}

The PEC performance results were collected by systematic photocurrent response tests as shown in Fig. 5. The dark current densities of all samples were first tested and are presented in Fig. 5(a), which clearly indicate no significant dark current, confirming 
that the photocurrent density mainly comes from photocatalytic water reaction. Fig. 5(b) displays the current density-potential $(J-V)$ curves of TG NWs under illumination. The current density increases with the increase of voltage for all samples. Compared with the pure $\mathrm{TiO}_{2} \mathrm{NWs}$, the TG NWs all display higher current density. The current density for $\mathrm{TiO}_{2}$, TG5, TG10, TG15, TG20, and TG25 were 0.08, 0.17, 0.36, 0.63, 1.10, 1.02 $\mathrm{mA} \mathrm{cm}{ }^{-2}$, respectively at $1.23 \mathrm{~V} v s \mathrm{RHE}$. As the shell thickness of the $\mathrm{GaO}_{\mathrm{x}} \mathrm{N}_{\mathrm{y}}$ modifier increases, the current density first shows an increase and then a decrease for the thickest $\mathrm{GaO}_{\mathrm{x}} \mathrm{N}_{\mathrm{y}}$ shell. Among all TG NWs samples, TG20 shows the highest current density of about $1.10 \mathrm{~mA} \mathrm{~cm}^{-2}$ at $1.23 \mathrm{~V}$ vs. RHE (i.e. $0.63 \mathrm{~V}$ vs $\mathrm{Ag} / \mathrm{AgCl}$ ), which is almost 14 times than that of our pure $\mathrm{TiO}_{2} \mathrm{NWs}\left(0.08 \mathrm{~mA} \mathrm{~cm}^{-2}\right)$. These results indicate that the fabrication of TG core-shell structure strongly enhances the photoactivity of $\mathrm{TiO}_{2} \mathrm{NWs}$ and this can be controlled by the thickness of the $\mathrm{GaO}_{\mathrm{x}} \mathrm{N}_{\mathrm{y}}$ shell deposited by ALD. The significant enhancement in current density is due to the advantageous features of TG core-shell heterostructure NWs. This structure results in efficient charge separation. In addition, other than the raised current density, the onset potentials of these TG NWs exhibited a remarkable and negative shift with respect to pure $\mathrm{TiO}_{2} \mathrm{NWs}$, which indicates that more $\mathrm{e}^{-}$are liberated and accumulated in the TG NWs. This can be attributed to favorable effect of $\mathrm{GaO}_{\mathrm{x}} \mathrm{N}_{\mathrm{y}}$, which decrease the kinetic energy barrier of charge transfer among the interface of $\mathrm{GaO}_{\mathrm{x}} \mathrm{N}_{\mathrm{y}}$ and $\mathrm{TiO}_{2} .{ }^{57}$

Fig. 5(c) displays the current-time (I-t) curves of pure $\mathrm{TiO}_{2}$ and different TG NWs. The transient photocurrent responses were conducted with the interval $15 \mathrm{~s}$ light 
ON/OFF cycle at $1.23 \mathrm{~V}$ ( $v s$ RHE). The enhanced photocurrent density changes in the order of $\mathrm{TG} 20>\mathrm{TG} 25>\mathrm{TG} 15>\mathrm{TG} 10>\mathrm{TG} 5>\mathrm{TiO}_{2}$, indicating that the $\mathrm{TG} 20$ is the optimum shell thickness to facilitate the separation of photogenerated charge carriers, which is in accordance with the previous $J-V$ measurement results. TG samples show good photoswitching properties with a rapid response speed, which is stable and reproducible. Obviously, the TG20 showed the maximum increase to $1.06 \mathrm{~mA} \mathrm{~cm}^{-2}$ in several cycles, which is almost 18 times higher than pure $\mathrm{TiO}_{2}\left(0.06 \mathrm{~mA} \mathrm{~cm}{ }^{-2}\right)$. The light current-dark current ratio of TG20 is $1.9 \times 10^{3}$ and the photocurrent decays to stable state in less than 1 s. Moreover, as shown in Fig. 5(d), the TG20 sample shows almost no changes in photocurrent density at fixed current even with $10 \mathrm{~h}$ of continuous light irradiation. The SEM images of TG20 before and after PEC measurement in Fig. S5 shows no noticeable degradation of the TG20 NWs. These results further demonstrate that TG20 has excellent structural stability and photoelectric durability. Electrochemical impedance spectroscopy (EIS) was also applied to analyse the interfacial charge transfer and separation efficiency between the electrolyte and sample. As shown in Fig. 5(e), the semicircle radius on the plot of TG samples are smaller than that of $\mathrm{TiO}_{2}$, revealing that the formation of core-shell structure between $\mathrm{TiO}_{2}$ and $\mathrm{GaO}_{\mathrm{x}} \mathrm{N}_{\mathrm{y}}$ enhances charge carrier separation and transport. Among these TG samples, TG20 possesses a more depressed semicircle, which demonstrates a faster charge carrier transfer rate and smaller resistance and compared to $\mathrm{TiO}_{2} \mathrm{NWs}$. Furthermore, the Nyquist plots can be fitted to the equivalent Randle circuit as shown in the inset of Fig. 5(e) for studying the impedance. In the equivalent Randle circuit, there are three 
main electronic components: the charge transfer resistance $\left(\mathrm{R}_{\mathrm{ct}}\right)$, the series resistance $\left(\mathrm{R}_{\mathrm{s}}\right)$, and constant phase element $(\mathrm{CPE}) .{ }^{58}$ The $\mathrm{R}_{\mathrm{ct}}$ reflects the charge transfer resistance at TG NWs electrode and electrolyte interface and within $\mathrm{TiO}_{2} \mathrm{NWs}$. This corresponds to a high frequency semicircle, which is equal to the second large semicircle in Fig. 5(e). In general, a smaller $\mathrm{R}_{\mathrm{ct}}$ means a faster reaction rate. Table $\mathrm{S} 1$ summarizes the values of $\mathrm{R}_{\mathrm{ct}}$ according to the electrochemical fit and simulation. Compared to other TG systems and $\mathrm{TiO}_{2}$ NWs, the TG20 shows the lowest $\mathrm{R}_{\mathrm{ct}}$ value, which confirms the improved separation efficiency of photogenerated carriers and the faster charge transfer at the interface of TG20 NWs and electrolyte. ${ }^{59}$

In order to illuminate the role of the $\mathrm{GaO}_{x} \mathrm{~N}_{y}$ shell in improved PEC performance, we also measured the incident photon to current conversion efficiency (IPCE) to characterize the wavelength dependent photoresponse. As displayed in Fig. 5(f), the IPCE spectra was obtained for pure $\mathrm{TiO}_{2} \mathrm{NWs}$ as well as for best photoresponsive TG20 NWs. The IPCE data collected from TG20 NWs displayed an enhancement over the entire wavelength range compared to pure $\mathrm{TiO}_{2} \mathrm{NWs}$. Further, the maximum IPCE value of $30.44 \%$ for $\mathrm{TiO}_{2} \mathrm{NWs}$ at the wavelength of $380 \mathrm{~nm}$ is significantly increased to a value of $92.08 \%$ at $380 \mathrm{~nm}$ for TG20. Although the IPCE is low in the longer wavelength, 400-460 nm, we can still see the enhanced IPCE values for TG20 compared to $\mathrm{TiO}_{2} \mathrm{NWs}$. These are consistent with the results of the absorption spectrum and PEC measurements. The increased IPCE values with increasing the wavelength suggests that $\mathrm{GaO}_{\mathrm{x}} \mathrm{N}_{\mathrm{y}}$ shell narrows the effective bandgap of $\mathrm{TiO}_{2} \mathrm{NWs}$, which 
improves the light collection and conversion efficiency particularly in the visible region. These results show that the unique TG core-shell NWs with appropriate shell thickness can enhance the PEC performance of $\mathrm{TiO}_{2}$ NWs.
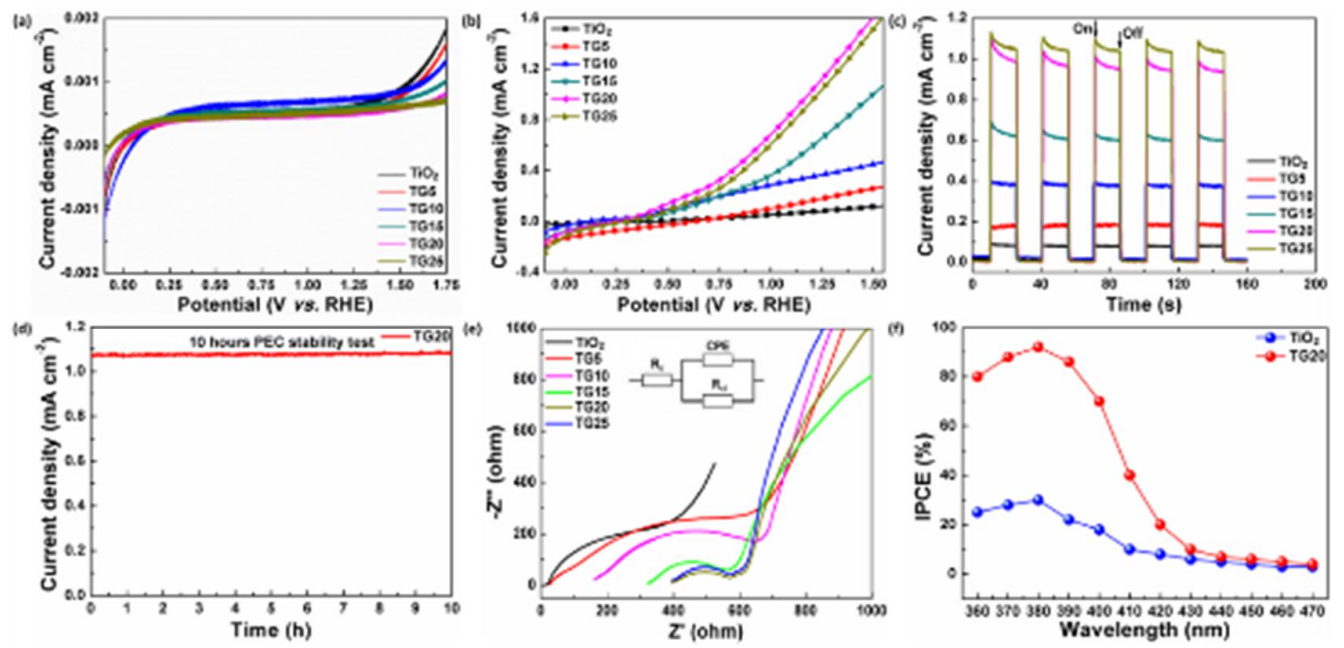

Fig.5 (a) LSV spectra in dark and (b) light, (c) I-t curves, (d) PEC stability studies of TG20 for $10 \mathrm{~h}$, (e) EIS plots, (f) IPCE spectra for $\mathrm{TiO}_{2}$ and TG20 NWs. The inset of (e) shows the equivalent fitting circuit.

In our work, the enhancement percentage (EP) for PEC performance of TG20 to $\mathrm{TiO} 2$ was calculated by the following formula and shown in Fig. A7.

Compared with the bare $\mathrm{TiO} 2$, the $20 \mathrm{~nm}-\mathrm{GaOxNy}$ modified $\mathrm{TiO} 2$ (TG20) shows enhanced PEC performance in the wavelength of $360-470 \mathrm{~nm}$, especially in the wavelength of $360-420 \mathrm{~nm}$. A small amount of $\mathrm{GaOxNy}$ modification cannot completely replace the function of $\mathrm{TiO} 2$, but only enhance the PEC performance of 
specific wavelength. In fact, a similar conclusion was drawn in our recent $\mathrm{ZnO}-\mathrm{GaON}$ system2. Therefore, it can be concluded that the enhancement of the PEC performance of the TG system compared to the $\mathrm{TiO} 2 \mathrm{NWs}$ is significant in the UV region and the enhancement is smaller under visible light irradiation.

Table 1 presents a comparison of the PEC performance of various $\mathrm{TiO}_{2}$ and $\mathrm{GaO}_{\mathrm{x}} \mathrm{N}_{\mathrm{y}}$ based photocatalysts. The single $\mathrm{TiO}_{2}$ and $\mathrm{Ga}$-based materials have rather low photocurrent density values, such as the $0.013 \mathrm{~mA} \mathrm{~cm}^{-1}$ for $\mathrm{TiO}_{2} \mathrm{NWs}^{60}{ }^{6}$ the $0.28 \mathrm{~mA}$ $\mathrm{cm}^{-1}$ for GaON nanosheets, ${ }^{24}$ and $0.20 \mathrm{~mA} \mathrm{~cm}^{-1}$ for flat porous GaN ${ }^{62}$ Similarly, the optimized $\mathrm{GaO}_{\mathrm{x}} \mathrm{N}_{\mathrm{y}}$ based composites still show low photocurrent density. For example, the photocurrent densities for $\mathrm{BiVO}_{4} / \mathrm{GaO}_{\mathrm{x}} \mathrm{N}_{1-\mathrm{x}}$ composite ${ }^{63}$ and for $(\mathrm{GaN})_{1-\mathrm{x}}(\mathrm{ZnO})_{\mathrm{x}}{ }^{64}$ are 0.37 and $0.03 \mathrm{~mA} \mathrm{~cm}^{-1}$. In contrast, the TG20 NWs synthesized by a combination of hydrothermal synthesis and PE-ALD deposition in this work already display a large photocurrent density of $1.10 \mathrm{~mA} \mathrm{~cm}^{-1}$ at $1.23 \mathrm{~V}$ vs RHE in $0.5 \mathrm{M} \mathrm{NaSO}_{4}$ solution.

Table 1 Comparison of the PEC performance of the $\mathrm{TiO}_{2}$ and $\mathrm{GaO}_{\mathrm{x}} \mathrm{N}_{\mathrm{y}}$ based photocatalysts.

\begin{tabular}{cccccc}
\hline Materials & Methods & Electrolytes & Applied voltage & Photocurrent density & Reference \\
& & & $(\mathbf{V})$ & $\left(\mathbf{m A ~ c m}^{-2}\right)$ \\
\hline $\mathrm{TiO}_{2} \mathrm{NWs}$ & Hydrothermal Method & $0.5 \mathrm{M} \mathrm{Na}_{2} \mathrm{SO}_{4}$ & $1.23 \mathrm{~V} \mathrm{vs} \mathrm{Ag/AgCl}$ & 0.013 & 60
\end{tabular}




\begin{tabular}{|c|c|c|c|c|c|}
\hline GaON Nanosheets & Hydrothermal Method & $0.5 \mathrm{M} \mathrm{Na}_{2} \mathrm{SO}_{4}$ & $0.60 \mathrm{~V}$ vs SCE & 0.28 & 24 \\
\hline$\beta-\mathrm{Ga}_{2} \mathrm{O}_{3}$ Nanoparticles & RF Sputtering & $1 \mathrm{M} \mathrm{NaCl}$ & $0.2 \mathrm{~V}$ vs $\mathrm{Ag} / \mathrm{AgCl}$ & 0.002 & 61 \\
\hline Flat porous $\mathrm{GaN}$ & Thermal Ammonia Treatment & $0.5 \mathrm{M} \mathrm{Na}_{2} \mathrm{SO}_{4}$ & $1.23 \mathrm{~V}$ vs $\mathrm{Ag} / \mathrm{AgCl}$ & 0.20 & 62 \\
\hline $\mathrm{BiVO}_{4} / \mathrm{GaO}_{\mathrm{x}} \mathrm{N}_{1-\mathrm{x}}$ & Sol-Gel Spin Coating & $0.5 \mathrm{M} \mathrm{K}_{3} \mathrm{PO}_{4}$ & $1.23 \mathrm{~V}$ vs $\mathrm{Ag} / \mathrm{AgCl}$ & 0.37 & 63 \\
\hline$(\mathrm{GaN})_{1-\mathrm{x}}(\mathrm{ZnO})_{\mathrm{x}}$ & Solution Method & $0.5 \mathrm{M} \mathrm{NaSO}_{4}$ & $1.23 \mathrm{~V}$ vs RHE & 0.03 & 64 \\
\hline $\mathrm{GaON} / \mathrm{TiO}_{2} \mathrm{NWs}$ & Hydrothermal Method \& & $0.5 \mathrm{M} \mathrm{NaSO}_{4}$ & 1.23 V vs RHE & 1.10 & This work \\
\hline
\end{tabular}

ALD

Origin of enhanced performance

The origin of enhanced PEC performance of the TG NWs is now discussed in detail. Firstly, as shown in Fig. 4(a), in the diffuse reflectance spectra of the $\mathrm{TiO}_{2} \mathrm{NWs}$ and our range of TG NWs we see that compared with pure $\mathrm{TiO}_{2} \mathrm{NWs}$, the TG NWs show a clear red shift of the absorption edge. This observed enhancement in visible light absorption is attributed to the strong effect of the $\mathrm{GaO}_{\mathrm{x}} \mathrm{N}_{\mathrm{y}}$ on the position of the valence band edge as discussed in the DFT results below. TG20 shows the strongest absorption ranging from 400 to $600 \mathrm{~nm}$. This can be due to the fact that the TG coreshell NWs provides a longer light transport path, ${ }^{65}$ thus enhancing the PEC performance. Secondly, in Fig. 6(a), we show results based on the finite difference time domain (FDTD) method, in which the electric-field distribution for single $\mathrm{TiO}_{2}, \mathrm{TG} 10$, and TG20 NWs were simulated at an excitation wavelength of $420 \mathrm{~nm}$. The corresponding simulation models are shown in detali in Fig. S6. To simplify the simulation model, the 
protrusion of the top of the nanowires is ignored, and the geometric dimension parameters are obtained according to the SEM and TEM results. The electric-field intensity in TG10 and TG20 are greatly enhanced compared with pure $\mathrm{TiO}_{2} \mathrm{NWs}$, and this indicates much higher possibilities for excitation of charge carriers in TG samples. In addition, the $\mathrm{GaO}_{\mathrm{x}} \mathrm{N}_{\mathrm{y}}$ shell thickness of $20 \mathrm{~nm}$ is the most favorable for light reflection and interference, and this can promote the diffusion and transfer of holes in the $\mathrm{TiO}_{2}$ core and $\mathrm{GaO}_{\mathrm{x}} \mathrm{N}_{\mathrm{y}}$ shell. ${ }^{66}$ Thus, in the present work, the enhancement of light absorption in the $\mathrm{TiO}_{2}$ core and $\mathrm{GaO}_{\mathrm{x}} \mathrm{N}_{\mathrm{y}}$ shell can more effectively promote the generation and separation of photoexcited $\mathrm{e}^{-}-\mathrm{h}^{+}$pairs, which drives the enhanced PEC performance of the core-shell NW structures.

Fig. 6(b) shows the VB XPS spectra of $\mathrm{TiO}_{2}$ and TG5. From the spectra, the valence band energy $\left(\mathrm{E}_{\mathrm{v}}\right)$ of $\mathrm{TiO}_{2}$ and TG5 are calculated to be 2.26 and $1.22 \mathrm{eV}$, respectively. From Fig. 4(b), the band gap of $\mathrm{TiO}_{2}$ and TG5 are estimated to be 3.20 and $3.10 \mathrm{eV}$, respectively. Thus, the conduction band energies $\left(\mathrm{E}_{\mathrm{c}}\right)$ are calculated to be - 0.94 and - 1.88 for $\mathrm{TiO}_{2}$ and TG5 versus normal hydrogen electrode (NHE) from $\mathrm{E}_{\mathrm{g}}-$ Ev. Notably, Compared with $\mathrm{TiO}_{2}$, TG5 has a higher CB minimum, as shown in Fig. 6(c), which can promote the electrons migration to the conduction band, thus enhancing reduction capacity and driving the reduction reaction more effectively. Iqbal et al., ${ }^{24}$ reported that the $\mathrm{E}_{\mathrm{CB}}$ and $\mathrm{E}_{\mathrm{VB}}$ of $\mathrm{GaON}$ are more negative than those of $\mathrm{TiO}_{2}$, which suggests that core-shell NW-TG structure can promote the transfer of electrons and holes. In terms of band structure, the $\mathrm{TiO}_{2}$ core and $\mathrm{GaO}_{\mathrm{x}} \mathrm{N}_{\mathrm{y}}$ shell structure achieves a 
favourable alignment. Moreover, the VB of TG5 is below the oxidation level for $\mathrm{H}_{2} \mathrm{O}$ to $\mathrm{O}_{2}$ while the $\mathrm{CB}$ is above the reduction level for $\mathrm{H}_{2} \mathrm{O}$ to $\mathrm{H}_{2} \cdot{ }^{47}$ Thirdly, based on the analysis above, to explain the improved PEC performance and stability of TG coreshell NWs, the charge transfer mechanism of photogenerated carriers is schematically shown in Fig. 6(d). The TG core-shell NWs show enhanced light harvesting capacity in both UV and visible region. It is well known that photogenerated carriers can be transferred from one semiconductor to another with suitable band alignment matching. Under light illumination, photo excitation will occur into the $\mathrm{CB}$ of the $\mathrm{TiO}_{2}$ core from the $\mathrm{GaO}_{\mathrm{x}} \mathrm{N}_{\mathrm{y}}$ shell, leaving holes in the $\mathrm{VB} .{ }^{67}$ The type-II band alignment, as shown in Fig. 6(c), promotes the transfer of photogenerated electrons from the $\mathrm{CB}$ of $\mathrm{GaO}_{\mathrm{x}} \mathrm{N}_{\mathrm{y}}$ to the $\mathrm{CB}$ of $\mathrm{TiO}_{2}$. Then the electrons transfer from $\mathrm{TiO}_{2}$ to FTO by the back contact, finally to the Pt counter electrode and can reduce $\mathrm{H}^{+}$to $\mathrm{H}_{2}$. On the other hand, the photogenerated holes migrate from $\mathrm{TiO}_{2}$ into the higher lying valence band states of $\mathrm{GaO}_{\mathrm{x}} \mathrm{N}_{\mathrm{y}}$ and can oxidise water molecules to generate $\mathrm{O}_{2}$. The recombination ratios of electrons and holes for example of TG20 is strongly decreased, as indicated by the PL results in Fig. 4(d). In addition, the Nyquist plots (Fig. 5(e)) further supported this result, indicating a more effective separation of electron holes, which enhances the PEC performance. 

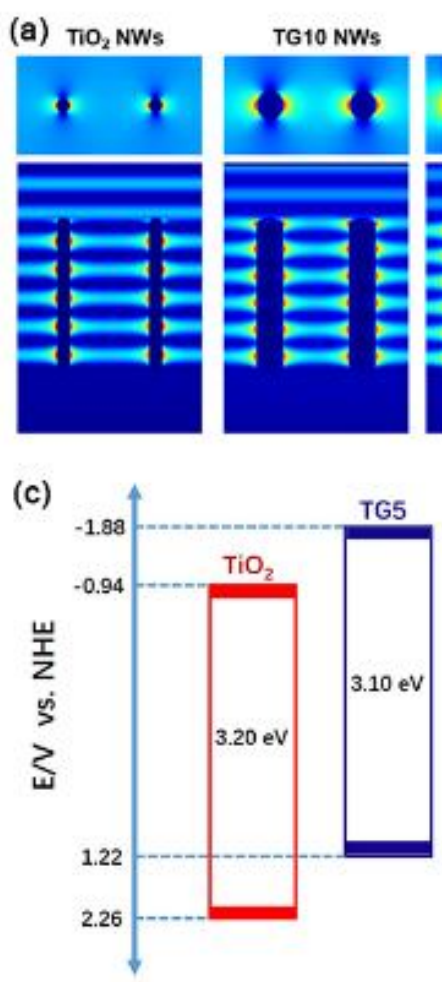

TG20 NWs

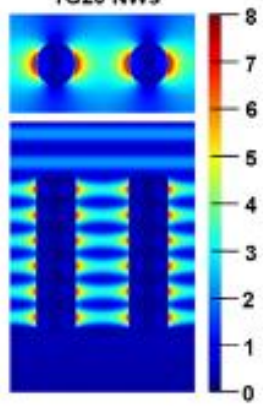

(b)

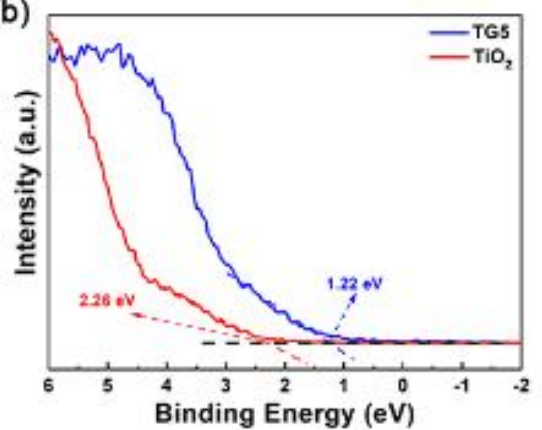

(d)

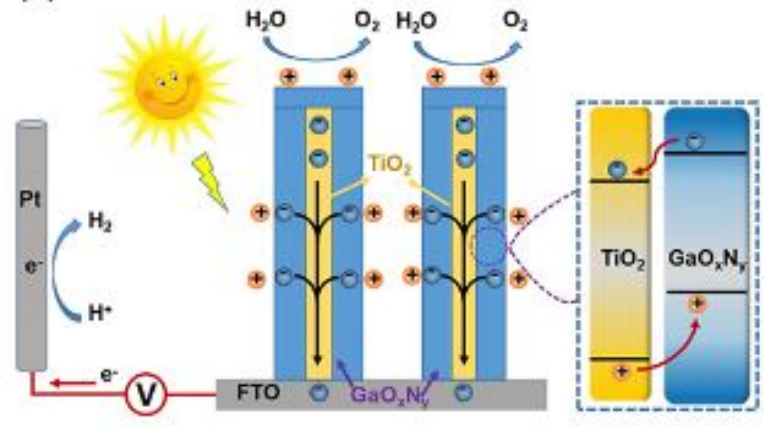

Fig.6 (a) Spatial distribution of electric-field for $\mathrm{TiO}_{2}$, TG10, and TG20 core-shell NWs in a longitudinal view with ultraviolet $(420 \mathrm{~nm})$ incidence, (b) valence-band XPS spectra, (c) band structure diagram of the TG5 and $\mathrm{TiO}_{2}$, and (d) schematic diagram of the PEC reaction mechanism of TG core-shell NWs.

We now discuss our results on DFT studies of a model $\mathrm{GaO}_{\mathrm{x}} \mathrm{N}_{\mathrm{y}}$-modified rutile (110) system. Firstly, we consider the formation of oxygen vacancies. As discussed in the experimental work earlier, this can be a key factor in the reactivity of these heterostructured core-shell materials. To investigate this aspect, we remove oxygen atoms from $\mathrm{GaO}_{\mathrm{x}} \mathrm{N}_{\mathrm{y}}$ and compute the oxygen vacancy formation energy in heterostructures with composition $\mathrm{Ga}_{6} \mathrm{O}_{5} \mathrm{~N}_{4}-\mathrm{TiO}_{2}$ and $\mathrm{Ga}_{6} \mathrm{O}_{6} \mathrm{~N}_{3}$ as described in Section 4. Fig. 7(a) and (b) display the atomic structure of two reduced $\mathrm{GaO}_{\mathrm{x}} \mathrm{N}_{\mathrm{y}}$-rutile (110) 
structures with compositions $\mathrm{Ga}_{6} \mathrm{O}_{4} \mathrm{~N}_{4}$ and $\mathrm{Ga}_{6} \mathrm{O}_{5} \mathrm{~N}_{3}$. The corresponding computed oxygen vacancy formation energies are $-0.5 \mathrm{eV}$ and $-0.3 \mathrm{eV}$, which means that these structures are more stable when off - stoichiometric due to loss of oxygen, which is consistent with the results from the experimental analysis.

Fig. 7(c) displays the projected electron density of states (PEDOS) plots for the example of the $\mathrm{GaO}_{4} \mathrm{~N}_{4}$-modified rutile (110) model system. The PEDOS is projected onto the Ti $3 \mathrm{~d}, \mathrm{Ga} 4 \mathrm{~s}$ and $4 \mathrm{p}$ and $\mathrm{O} 2 \mathrm{p} / \mathrm{N} 2 \mathrm{p}$ states and the bottom row shows the PEDOS around the valence and conduction band edges. For this and all examined GaONmodified rutile (110) structures we find new states in the original rutile valance to conduction band energy gap, which arise from the modification of rutile (110) with the $\mathrm{GaO}_{\mathrm{x}} \mathrm{N}_{\mathrm{y}}$ clusters. The highest occupied states lie at higher energy than the $\mathrm{TiO}_{2}$ valance band edge, while the bottom of the conduction band is composed of Ti $3 \mathrm{~d}$ states from the surface. The character of the highest occupied electronic states and the lowest conduction band states from the DFT+U analysis is consistent with the experimental results described above. While the quantitative changes in the energy gap cannot be fully captured by the DFT+U approach due to the inherent band gap underestimation, the introduction of new states in the energy gap arising from the $\mathrm{GaO}_{\mathrm{x}} \mathrm{N}_{\mathrm{y}}$ modification and a red shift in light absorption to longer wavelength is consistent with the experimental findings, confirming that this interfacial system can enhance visible light absorption. The presence of $\mathrm{GaO}_{\mathrm{x}} \mathrm{N}_{\mathrm{y}}$ - derived electronic states in the $\mathrm{TiO}_{2}$ band gap persists upon reduction so the light absorption properties will not be affected by the 
stoichiometry.

Upon reduction, the two electrons released after loss of oxygen localize onto two Ti atoms of the $\mathrm{TiO}_{2}$ surface, one of which lies directly under the $\mathrm{GaO}_{\mathrm{x}} \mathrm{N}_{\mathrm{y}}$ modifier and the second electron localizes on a Ti site in the subsurface layer. This reduction of Tis confirmed by computed Bader charges of 1.7 and 1.8 electrons for these Ti (giving net charges of 2.3 and 2.2 electrons) and computed spin magnetisations of $0.85 \mu_{\mathrm{B}}$, both of which are consistent with a $\mathrm{Ti}^{3+}$ oxidation state.

(a)

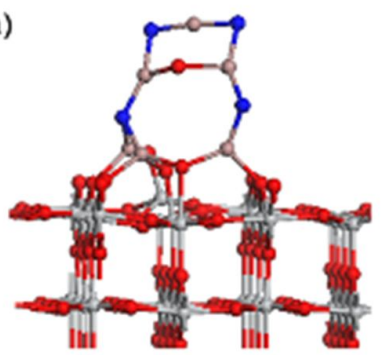

(b)

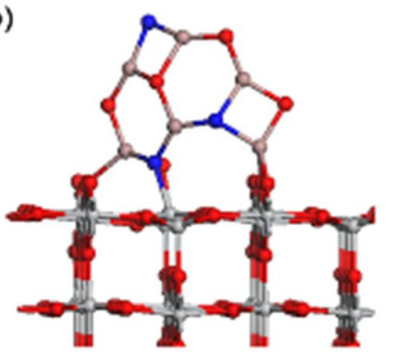

(c)

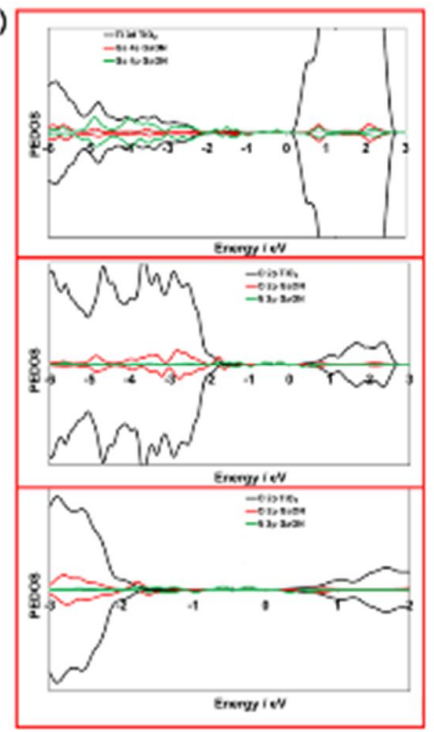

(d)
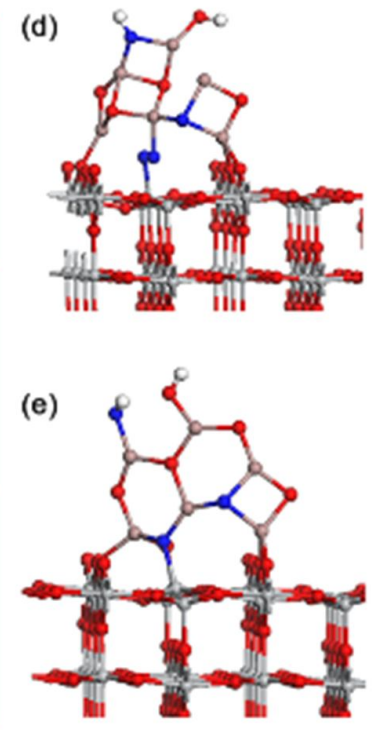

Fig.7 (a) Atomic structure of a reduced $\mathrm{Ga}_{6} \mathrm{O}_{4} \mathrm{~N}_{4}$-rutile structure formed by removing oxygen from $\mathrm{Ga}_{6} \mathrm{O}_{5} \mathrm{~N}_{4}$-rutile (110), (b) Atomic structure of a reduced $\mathrm{Ga}_{6} \mathrm{O}_{5} \mathrm{~N}_{3}$-rutile structure formed by removing oxygen from $\mathrm{Ga}_{6} \mathrm{O}_{8} \mathrm{~N}_{3}$-rutile (110), (c) Projected electronic density of states for the structure in (a), with the Fermi energy set to $0 \mathrm{eV}$. (d) Atomic structure of water adsorbed at reduced $\mathrm{Ga}_{6} \mathrm{O}_{4} \mathrm{~N}_{4}$-rutile, (e) Atomic structure of water adsorbed at reduced $\mathrm{Ga}_{6} \mathrm{O}_{5} \mathrm{~N}_{3}$-rutile. The grey spheres represent $\mathrm{Ti}$, red spheres 
O, blue spheres N, salmon spheres Ga and white spheres $\mathrm{H}$.

We now consider the adsorption of water at the $\mathrm{TiO}_{2} @ \mathrm{Ga}_{6} \mathrm{O}_{4} \mathrm{~N}_{4}$ and the $\mathrm{TiO}_{2} @ \mathrm{Ga}_{6} \mathrm{O}_{5} \mathrm{~N}_{3}$ structures, in which both have a reducing oxygen vacancy. The relaxed water adsorption structures are shown in Fig. 7(d) and (e). The initial adsorption mode of water is molecular and upon relaxation, the water molecule always dissociates to form a hydroxyl ( $\mathrm{OH}$ from water) and an $\mathrm{NH}$ species. The computed dissociative adsorption energies of a water molecule are $-0.72 \mathrm{eV}$ and $-1.07 \mathrm{eV}$, suggesting a strong interaction between water and the TG system. However, the magnitude of the adsorption energy of water is moderate which suggests that the dissociated water is not merely forming a strongly bound hydroxyl species but can instead be active in the water oxidation process to produce oxygen. The direct dissociation of water is promoted by the presence of the reduced cations after forming the oxygen vacancy, which has been discussed in other studies. ${ }^{68,69}$

\section{Conclusions}

In summary, the $\mathrm{TiO}_{2} @ \mathrm{GaO}_{\mathrm{x}} \mathrm{N}_{\mathrm{y}}$ core-shell nanowires photocathode for solar water splitting have been fabricated through hydrothermal and ALD technology and studied photoelectrochemically. By precise controlling the thickness of $\mathrm{GaO}_{\mathrm{x}} \mathrm{N}_{\mathrm{y}}$ shell from ALD, when the thickness of $\mathrm{GaO}_{\mathrm{x}} \mathrm{N}_{\mathrm{y}}$ is $20 \mathrm{~nm}$, the TG20 core-shell NWs shows a significant photocurrent density of $1.10 \mathrm{~mA} \mathrm{~cm}^{-2}$ at $1.23 \mathrm{~V}$ vs. RHE under AM $1.5 \mathrm{G}$ irradiation, which is 14 times larger than that of $\mathrm{TiO}_{2}$ NWs. The TG20 also exhibits good stability. The enhanced PEC performance are attributed to the extended visible 
light absorption, proper band alignment in TG core-shell system, making the effectively generation and transformation of photoexcited electrons and holes, and avoiding the interfacial recombination. In addition, the results of FDTD simulations and DFT calculations also suggest that the significant enhanced PEC performance in TG system for the existence of $\mathrm{GaO}_{\mathrm{x}} \mathrm{N}_{\mathrm{y}}$ cluster, which is in accordance with the results of our experiment. It is anticipated that this approach may have considerable effect on the development of highly efficient and stable $\mathrm{GaO}_{\mathrm{x}} \mathrm{N}_{\mathrm{y}}$ and $\mathrm{TiO}_{2}$ based nanoarchitectures for environment sustainability.

\section{Acknowledgments}

This work is supported by the National Key R\&D Program of China (No.2016YFE0110700), National Natural Science Foundation of China (No. U1632121, 11804055, 51861135105 and 61874034), Natural Science Foundation of Shanghai (No. 18ZR1405000), and China Postdoctoral Science Foundation (No. 2018M631997). This work is also supported by the Fudan University Exchange Program Scholarship for Doctoral Students. The work at Tyndall Institute is supported by Science Foundation Ireland through the SFI-NSF China Partnership Program, Grant Number SFI 17/NSFC/5279 NITRALD. We acknowledge access to computing resources at Tyndall supported by SFI and access to the SFI/DES/HEA funded Irish Center for High End Computing. The authors would also like to thank Prof. Xiaoxiang Xu of Tongji University and Prof. Yifang Chen of Fudan University, for the tests of photoelectrochemical performance and scanning electron microscopy. 


\section{Notes and references}

1G. Yilmaz, C.F. Tan, Y.F. Lim and G.W. Ho, Adv. Energy Mater., 2019, 9, 1802983.

2 J. Wang, C. Xue, W.Q. Yao, J. Liu, X.X. Gao, R.L. Zong, Z. Yang, W.J. Jin and D.P. Tao, Appl. Catal. B - Environ., 2019, 250, 369-381.

3 X.C. Huai, L. Girardi, R. Lu, S. Gao, Y. Zhao, Y.H. Ling, G.A. Rizzi, G. Granozzi and Z.J. Zhang, Nano Energy, 2019, 65, 104020.

4 H. Li, P. Wen, D.S. Itanze, M.W. Kim, S. Adhikari, C. Lu, L. Jiang, Y.J. Qiu and S.M. Geyer, Adv. Mater., 2019, 31, 1900813.

5 S.C. Wang, G. Liu and L.Z. Wang, Chem. Rev., 2019, 119, 5192-5247.

6 A. Fujishima and K. Honda, Nature, 1972, 238, 37-38.

7 N. Wei, Y. Liu, M. Feng, Z.X. Li, S.G. Chen, Y.B. Zheng and D.A. Wang, Appl. Catal. B - Environ., 2019, 244, 519-528.

8 L. Kang, L.P. Han, J.B. He, H.R. Li, T.T. Yan, G.R. Chen, J.P. Zhang, L.Y. Shi and D.S. Zhang, Environ. Sci. Technol., 2019, 53, 938-945.

9 Y. Liu, J. Xu, H.R. Li, S.X. Cai,H. Hu, C. Fang, L.Y. Shi and D.S. Zhang, J. Mater. Chem. A, 2015, 3, 11543-11553.

10 K.W. Zha, C. Feng, L.P. Han, H.R. Li, T.T. Yan, S.C. Kuboon, L.Y. Shi and D.S. Zhang, Chem. Eng. J., 2020,381, 122764. 
11 J. Deng, Y.D. Su, D. Liu, P.D. Yang, B. Liu and C. Liu, Chem. Rev., 2019, 119, 9221 9259.

12 W. Yang and J. Moon, ChemSusChem, 2019, 12, 1889-1899.

13 H.P. Zhou, M.L. Feng, K. Song, B. Liao, Y.C. Wang, R.C. Liu, X.N. Gong, D.K. Zhang, L.F. Cao and S.J. Chen, Nanoscale, 2019, 11, 22871.

14 K. Wang, D.W. Huang, L. Yu, K. Feng, L.T. Li, T. Harada, S. Ikeda and F. Jiang, ACS Catal., 2019, 9, 3090-3097.

15 N. Arai, N. Saito, H. Nishiyama, K. Domen, H. Kobayashi and Y. Inoue, Catal. Today, 2007, 129, 407-413.

16 H. Bae, H. Kim, J.W. Ju, D.W. Jeon, S.W. Ryu, Y. Moon and J.S. Ha, J. Electrochem. Soc., 2019, 166, H103-H107.

17 M.A. Hassan, J.H. Kang, M.A. Johar, J.S. Ha and S.W. Ryu, Acta Mater., 2018, 146, $171-175$.

18 H.P. Ma, J.H. Yang, J.J. Tao, K.P. Yuan, P.H. Cheng, W. Huang, J.C. Wang, Q.X. Guo, H.L. Lu and D.W. Zhang, Nano Energy, 2019, 66, 104089.

19 S.S. Patil, M.A. Johar, M.A. Hassan, D.R. Patil and S.W. Ryu, Appl. Catal. B Environ., 2018, 237, 791-801.

20 H.Y. Chen, L.P. Wang, J.M. Bai, J.C. Hanson, J.B. Warren, J.T. Muckerman, E. Fujita and J.A. Rodriguez, J. Phys. Chem. C, 2010, 114, 1809-1814. 
21 I. Khan, A. Qurashi, G. Berdiyorov, N. Iqbal, K. Fuji and Z.H. Yamani, Nano Energy, 2018, 44, 23-33.

22 S. Yu, B. Liu, Q. Wang, Y. Gao, Y. Shi, X. Feng, X. An, L. Liu and J. Zhang, ACS Appl. Mater. Interfaces, 2014, 6, 10283-10295.

23 M. Zhong, Y. Ma, P. Oleynikov, K. Domen and J.J. Delaunay, Energy Environ. Sci., 2014, 7, 1693-1699.

24 N. Iqbal, I. Khan, Z.H. Yamani and A. Qurashi, Sci. Rep., 2016, 6, 32319.

25 C.C. Hu and H. Teng, J. Phys. Chem. C, 2010, 114, 20100-20106.

26 J.J. Tao, H.L. Lu, Y. Gu, H.P. Ma, X. Li, J.X. Chen, W.J. Liu, H. Zhang and J.J. Feng, Appl. Surf. Sci., 2019, 476, 733-740.

27 S.C. Han, Y.C. Pu, L.X. Zheng, L.F. Hu, J.Z. Zhang and X.S. Fang, J. Mater. Chem. A, 2016, 4, 1078-1086.

28 G. Kresse and J. Hafner, Phys. Rev. B, 1994, 49, 14251-14269.

29 G. Kresse and D. Joubert, Phys. Rev. B, 1999, 59, 1758-1775.

30 J.P. Perdew, J.A. Chevary, S.H. Vosko, K.A. Jackson, M.R. Pederson, D.J. Singh and C. Fiolhais, Phys. Rev. B, 1992, 46, 6671-6687.

31 M. Nolan, Phys. Chem. Chem. Phys., 2011, 13, 18194-18199.

32 S.L. Dudarev, G.A. Botton, S.Y. Savrasov, C.J. Humphreys and A.P. Sutton, Phys. Rev. $B, 1998, \mathbf{5 7}, 1505-1509$. 
33 G. Henkelman, A. Arnaldsson and H. Jónsson, Comp. Mater. Sci., 2006, 36, 354360.

34 H.L Huang, X.L. Hou, J.R. Xiao, L. Zhao, Q.Y. Huang, H. Chen and Y.D. Li, Catal. Today, 2018, 330, 189-194.

35 D. Machon, N.L. Bail, P. Hermet, T. Cornier, S. Daniele and S. Vignoli, J. Phys. Chem. C, 2019, 123, 1948-1953.

36 L.K. Dhandole, M.A. Mahadik, S.G. Kim, H.S. Chung, Y.S. Seo, M. Cho, J.H. Ryu and J.S. Jang, ACS Appl. Mater. Interfaces, 2017, 9, 23602-23613.

37 R. Gopal, A. Goyal, A. Saini, M. Nagar, N. Sharma, D.K. Gupta and V. Dhayal, Ceram. Int., 2018, 44, 19099-19105.

38 H.Y. Chen, H.L. Lu, J.X. Chen, F. Zhang, X.M. Ji, W.J. Liu, X.F. Yang and D.W. Zhang, ACS Appl. Mater. Interfaces, 2017, 9, 38662-38669.

39 J.J. Tao, Z.Z. Gong, G. Yao, Y.L. Cheng, M. Zhang, J.G. Lv, S.W. Shi, G. He, X.S. Jiang, X.S. Chen and Z.Q. Sun, J. Alloy. Compd., 2016, 688, 605-612.

40 G.M. Wang, H.Y. Wang, Y.C. Ling, Y.C. Tang, X.Y. Yang, R.C. Fitzmorris, C.C. Wang, J.Z. Zhang and Y. Li, Nano Lett., 2011, 11, 3026-3033.

41 J.J. Tao, H.L. Lu, Y. Gu, H.P. Ma, X. Li, J.X. Chen, W.J. Liu, H. Zhang and J.J. Feng, Appl. Surf. Sci., 2019, 476, 733-740.

42 S.M. He, Y.Y. Meng, Q.L. Wu, J.L. Yang, S.C. Huang, X.H. Li, S.F. Tong, T. Asefa 
and M.M. Wu, Nanoscale, 2018, 10, 19367-19374.

43 K. Maeda, T. Takata, M. Hara, N. Saito, Y. Inoue, H. Kobayashi and K. Domen, J. Am. Chem. Soc., 2005, 127, 8286-8287.

44 F. Wang, X.X. He, L.M. Sun, J.Q. Chen, X.J. Wang, J.H. Xu and X.G. Han, J. Mater. Chem. A, 2018, 6, 2091-2099.

45 W. Wei, Z. Qin, S. Fan, Z. Li, K. Shi, Q. Zhu and G. Zhang, Nanoscale Res. Lett., $2012,7,562$.

46 M. Myers, F.L.M. Khir, M.A. Home, C. Mennell, J. Gillbanks, A. Tadich, M.V. Baker, B.D. Nener and G. Parish, Appl. Surf. Sci., 2018, 435, 23-30.

47 F. Guo, W.L. Shi, C. Zhu, H. Li and Z.H. Kang, Appl. Catal. B - Environ., 2018, 226, 412-420.

48 J.J. Li, S.C. Cai, E.Q. Yu, B. Weng, X. Chen, J. Chen, H.P. Jia and Y.J. Xu, Appl. Catal. B - Environ., 2018, 233, 260-271.

49 P. Li, H. Hu, J. Xu, H. Jing, H. Peng, J. Lu, C. Wu and S. Ai, Appl. Catal. B - Environ., 2014, 147, 912-919.

50 I.M. Høiaas, A.L. Mulyo, P.E. Vullum, D.C. Kim, L. Ahtapodov, B.O. Fimland, K. Kishino and H. Weman, Nano Lett., 2019, 19, 1649-1658.

51 K. Meada and K. Domen, Chem. Mater., 2010, 22, 612-623.

52 S. Shokhovets, L. Kirste, J.H. Leach, S. Krischok and M. Himmerlich, J. Appl. Phy, 
2017, 122, 045706.

53 L. Li, J. Yan, T. Wang, Z. Zhao, J. Zhang, J. Gong and N. Guan, Nat. Comm., 2015, 6, 5881-5890.

54 M. Nolan, A. Lwaszuk, A.K. Lucid, J.J. Carey and M. Fronzi, Adv. Mater, 2016, 28, $5425-5446$.

55 A. Iwaszuk, M. Nolan, Q.L. Jin, M. Fujishima and H. Tada, J. Phys. Chem. C, 2013, 117, 2709-2718.

56 F. Tian, Y.P. Zhang, J. Zhang and C.X. Pan, J. Phys. Chem. C, 2012, 116, 7515-7519.

57 S.X. Liu, L.X. Zheng, P.P. Yu, S.C. Han and X.S. Fang, Adv. Funct. Mater, 2016, 26, 3331-3339.

58 L.X. Zheng, W.W. Hu, X.W. Shu, H.J. Zheng and X.S. Fang, Adv. Mater. Interfaces, $2018,5,1800515$.

59 Y.J. Zhong, Z.S. Li, X. Zhao, T. Fang, H.T. Huang, Q.F. Qian, X.F. Chang, P. Wang, S.C. Yan, Z.T. Yu and Z.G. Zou, Adv. Funct. Mater., 2016, 26, 7156-7163.

60 Y.F. Wang, M. Zhang, H. Yu, Y. Zuo, J. Gao, G. He and Z.Q. Sun, Appl. Catal. B Environ., 2019, 252, 174-186.

61 S.J. Chang, Y.L. Wu, W.Y. Weng, Y.H. Lin, W.K. Hsieh, J.K. Sheu and C.L. Hsu, J. Electrochem. Soc., 2014, 161, H508-H511.

62 H.J. Kim, J. Park, B.U. Ye, C.J. Yoo, J.L. Lee, S.W. Ryu, H. Lee, K.J. Choi and J.M. 
Baik, ACS Appl. Mater. Interfaces, 2016, 8, 18201-18207.

63 B.K. Kang, G.S. Han, J.H. Baek, D.G. Lee, Y.H. Song, S. Bin Kwon, I.S. Cho, H.S. Jung and D.H. Yoon, Adv. Mater. Interfaces, 2017, 4, 1700323.

64 J. Li, B.D. Liu, A.M. Wu, B. Yang, W.J. Yang, F. Liu, X.L. Zhang, V. An and X. Jiang, Inorg. Chem., 2018, 57, 5240-5248.

65 K.P. Yuan, Q. Cao, H.L. Lu, M. Zhong, X.Z. Zheng, H.Y. Chen, T. Wang, J.J. Delaunay, W. Luo, L.W. Zhang, Y.Y. Wang, Y.H. Deng, S.J. Ding and D.W. Zhang, J. Mater. Chem. A, 2017, 5, 14697-14706.

66 Z.M. Bai, X.Q. Yan, Y. Li, Z. Kang, S.Y. Cao and Y. Zhang, Adv. Energy Mater., 2016, 6, 1501459.

67 H. Ali, N. Ismail, A. Hegazy and M. Mekewi, Electrochim. Acta, 2014, 150, $314-$ 319.

68 S. Kenmoe, O. Lisovski, S. Piskunov, D. Bocharov, Y.F. Zhukovskii and E. Spohr, J. Phys. Chem. B, 2018, 122, 5432-5440.

69 I.M. Nadeem, J.P.W. Treacy, S. Selcuk, X. Torrelles, H. Hussain, A. Wilson, D. C. Grinter, G. Cabailh, O. Bikondoa, C. Nicklin, A. Selloni, J. Zegenhagen, R. Lindsay and G. Thornton, J. Phys. Chem. Lett., 2018, 9, 3131-3136. 